\title{
Highly tunable TetR-dependent target gene expression in the acetic acid bacterium Gluconobacter oxydans
}

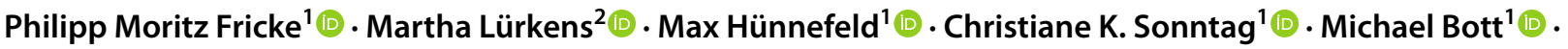 \\ Mehdi D. Davari ${ }^{3}$ (D) Tino Polen ${ }^{1}$ (D)
}

Received: 18 June 2021 / Revised: 22 July 2021 / Accepted: 23 July 2021 / Published online: 27 August 2021

(c) The Author(s) 2021

\begin{abstract}
For the acetic acid bacterium (AAB) Gluconobacter oxydans only recently the first tight system for regulatable target gene expression became available based on the heterologous repressor-activator protein AraC from Escherichia coli and the target promoter $\mathrm{P}_{a r a B A D}$. In this study, we tested pure repressor-based TetR- and LacI-dependent target gene expression in G. oxydans by applying the same plasmid backbone and construction principles that we have used successfully for the araC-P $\mathrm{P}_{\text {araBAD }}$ system. When using a pBBR1MCS-5-based plasmid, the non-induced basal expression of the Tn10-based TetR-dependent expression system was extremely low. This allowed calculated induction ratios of up to more than 3500-fold with the fluorescence reporter protein $\mathrm{mNeonGreen}(\mathrm{mNG})$. The induction was highly homogeneous and tunable by varying the anhydrotetracycline concentration from 10 to $200 \mathrm{ng} / \mathrm{mL}$. The already strong reporter gene expression could be doubled by inserting the ribosome binding site AGGAGA into the 3' region of the $\mathrm{P}_{\text {tet }}$ sequence upstream from $m N G$. Alternative plasmid constructs used as controls revealed a strong influence of transcription terminators and antibiotics resistance gene

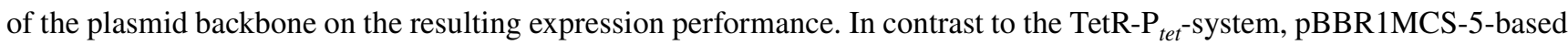
LacI-dependent expression from $\mathrm{P}_{\text {lacUV5 }}$ always exhibited some non-induced basal reporter expression and was therefore tunable only up to 40 -fold induction by IPTG. The leakiness of $\mathrm{P}_{\text {lac UVV }}$ when not induced was independent of potential readthrough from the lacI promoter. Protein-DNA binding simulations for $\mathrm{pH} 7,6,5$, and 4 by computational modeling of LacI, TetR, and AraC with DNA suggested a decreased DNA binding of LacI when $\mathrm{pH}$ is below 6, the latter possibly causing the leakiness of LacI-dependent systems hitherto tested in AAB. In summary, the expression performance of the pBBR1MCS5-based TetR-P ${ }_{t e t}$ system makes this system highly suitable for applications in G. oxydans and possibly in other AAB.
\end{abstract}

Key Points

- A pBBRIMCS-5-based TetR-P $P_{\text {tet }}$ system was tunable up to more than 3500-fold induction.

- A pBBRIMCS-5-based LacI-P lacUV5 system was leaky and tunable only up to 40-fold.

- Modeling of protein-DNA binding suggested decreased DNA binding of LacI at $p H<6$.

Keywords Promoter $\cdot$ Induction $\cdot$ Expression $\cdot$ Plasmid $\cdot \mathrm{mNeonGreen} \cdot$ Membrane-bound dehydrogenase

Tino Polen

t.polen@fz-juelich.de

Philipp Moritz Fricke

p.fricke@fz-juelich.de

Martha Lürkens

martha.luerkens@rwth-aachen.de

Max Hünnefeld

m.huennefeld@fz-juelich.de

Christiane K. Sonntag

c.sonntag@fz-juelich.de

Michael Bott

m.bott@fz-juelich.de
Mehdi D. Davari

mehdi.davari@ipb-halle.de

1 Forschungszentrum Jülich GmbH, IBG-1: Biotechnology, Institute of Bio- and Geosciences, 52425 Jülich, Germany

2 RWTH Aachen University, Institute of Biotechnology, Worringerweg 3, 52074 Aachen, Germany

3 Department of Bioorganic Chemistry, Leibniz Institute of Plant Biochemistry, Weinberg 3, 06120 Halle, Germany 


\section{Introduction}

The acetic acid bacterium (AAB) Gluconobacter oxydans harbors the beneficial ability of regio- and stereoselective incomplete oxidation of a variety of substrates (e.g., sugars and sugar alcohols) in the periplasm by membrane-bound dehydrogenases $(\mathrm{mDHs})$ and release of resulting products into the cultivation medium (Mamlouk and Gullo 2013; Mientus et al. 2017; Pappenberger and Hohmann 2014). Because of this feature, G. oxydans is industrially used for oxidative biotransformations of carbohydrates to produce e.g. the vitamin $\mathrm{C}$ precursor $\mathrm{L}$-sorbose, the tanning lotion additive dihydroxyacetone, and 6-amino-L-sorbose used for the production of the antidiabetic drug miglitol (Ameyama et al. 1981; Gupta et al. 2001; Hekmat et al. 2003; Saito et al. 1997; Tkac et al. 2001; Wang et al. 2016).

For the expression of target genes in G. oxydans, so far only constitutive promoters have been used due to the lack of a regulatable promoter demonstrated to be functional and tunable in G. oxydans (reviewed in Fricke et al. 2021). Only recently the first tight system became available for tunable induction of gene expression in G. oxydans. This system is based on AraC- $\mathrm{P}_{a r a B A D}$ and the induction by $\mathrm{L}$-arabinose binding to the regulator protein AraC (Fricke et al. 2020). AraC typically represses the target promoter $\mathrm{P}_{\text {araBAD }}$ by DNA bending in the absence of the inducer $\mathrm{L}$-arabinose and activates it in the presence of the inducer by a modified binding to the promoter DNA and thereby releasing the bending (Schleif 2010). However, in G. oxydans, $\mathrm{P}_{\text {araBAD }}$ is almost not active in the absence of araC and thus, repression by $\mathrm{AraC}$ is not required in G. oxydans for tightness of $\mathrm{P}_{a r a B A D}$ in the absence of the inducer (Fricke et al. 2020). In contrast, in Gluconacetobacter and Komagataeibacter plasmid-based AraC-P $\mathrm{P}_{\text {araBAD }}$ was reported to be very leaky (Teh et al. 2019). While AraC typically is acting both as repressor and activator, the transcriptional regulators TetR and LacI only exert a repressor function and dissociate from their operator DNA when forming a complex with their respective inducer (Hillen et al. 1983; Khoury et al. 1991; Miller 1970; Sellitti et al. 1987; Wray and Reznikoff 1983). $\mathrm{P}_{\text {tet }}$ and $\mathrm{P}_{l a c}$ then enable transcription of the downstream gene by RNA polymerase. In AAB both TetR- and LacI-dependent target gene expression have so far been reported to be very leaky or inhomogeneously induced. In Komagataeibacter rhaeticus iGEM, the TetR-P ${ }_{t e t}$ system from transposon $\mathrm{Tn} 10$ exhibited only approximately 1.5 -fold induction due to high leakiness in the absence of the inducer anhydrotetracycline (Florea et al. 2016). With a LacI-based expression system in $K$. xylinus, the induction ratio also appeared to be low and only a fraction of cells showed some induction (Liu et al. 2020). For another LacI-based system, expression was also found to be very leaky in G. oxydans (Condon et al. 1991).

In this study, we aimed to test TetR- and LacI-dependent target gene expression in $G$. oxydans by applying the same plasmid backbone and construction principles that we have used recently for the construction of the araC- $\mathrm{P}_{\text {araBAD }}$ system (Fricke et al. 2020). With pBBR1MCS-5-based plasmid constructs, we found always some leakiness of the LacI-P lacuv 5 system, yet extremely tight and optimally tunable target gene expression with TetR- $\mathrm{P}_{t e t}$ making the latter system highly suitable for applications in $G$. oxydans and possibly in other AAB.

\section{Materials and methods}

\section{Bacterial strains, plasmids, and culture conditions}

All strains and plasmids created and used in this study are listed in Table 1. G. oxydans was routinely cultivated in D-mannitol medium ( $\mathrm{pH}$ 6) containing 4\% (w/v) D-mannitol, $5 \mathrm{~g} \mathrm{~L}^{-1}$ yeast extract, $2.5 \mathrm{~g} \mathrm{~L}^{-1} \mathrm{MgSO}_{4} \times 7 \mathrm{H}_{2} \mathrm{O}, 1 \mathrm{~g} \mathrm{~L}^{-1}$ $\left(\mathrm{NH}_{4}\right)_{2} \mathrm{SO}_{4}, 1 \mathrm{~g} \mathrm{~L}^{-1} \mathrm{KH}_{2} \mathrm{PO}_{4}$ at $30^{\circ} \mathrm{C}$ and $180 \mathrm{rpm}$, and supplemented with $50 \mu \mathrm{g} \mathrm{mL}^{-1}$ sodium cefoxitin. Besides D-mannitol and cefoxitin which were sterile filtered as stock solutions $\left(20 \%(\mathrm{w} / \mathrm{v})\right.$ and $\left.50 \mathrm{mg} \mathrm{mL}^{-1}\right)$, all components were autoclaved for sterilization $\left(120^{\circ} \mathrm{C}, 20 \mathrm{~min}\right)$. Unless stated otherwise, for shake flask cultivations $10 \mathrm{~mL}$ or $60 \mathrm{~mL}$ of D-mannitol medium was inoculated from overnight precultures to an initial optical density at $600 \mathrm{~nm}\left(\mathrm{OD}_{600}\right)$ of 0.3 or 0.2 (UV-1800, Shimadzu) using $100 \mathrm{~mL}$ or $500 \mathrm{~mL}$ shaking flasks with three baffles. G. oxydans carrying pBBR1MCS-5- or pBBR1MCS-2-based plasmids were supplemented with $10 \mu \mathrm{g} \mathrm{mL}^{-1}$ gentamicin or $50 \mu \mathrm{g} \mathrm{mL}^{-1}$ kanamycin, respectively (Kovach et al. 1995). Escherichia coli strains were routinely grown at $37{ }^{\circ} \mathrm{C}$ and $160 \mathrm{rpm}$ in lysogeny broth (LB) medium which was supplemented when appropriate with $10 \mu \mathrm{g} \mathrm{mL}^{-1}$ gentamicin or $50 \mu \mathrm{g} \mathrm{mL}^{-1} \mathrm{kan}$ amycin. G. oxydans was transformed by conjugal transfer of plasmids from $E$. coli S17-1 (Kiefler et al. 2017). Competent E. coli cells were prepared by $\mathrm{CaCl}_{2}$ procedure and transformed as described (Hanahan 1983).

\section{Recombinant DNA work}

All DNA oligonucleotides used for the construction of plasmids and sequencing are listed in Table S1 and were synthesized by Eurofins MWG. All restriction enzymes were purchased from Thermo Scientific. Polymerase chain reaction (PCR), restriction, and ligation reactions for DNA manipulations were conducted according to standard protocols (Sambrook et al. 1989). DNA fragments were amplified using Q5 polymerases according to 
Table 1 Strains and plasmids used or constructed in this study

\begin{tabular}{|c|c|c|}
\hline & Relevant characteristics & Reference / Source \\
\hline \multicolumn{3}{|l|}{ Strain } \\
\hline E. coli $\mathrm{S} 17-1$ & $\Delta r e c A$, endA1, hsdR17, supE44, thi- 1, tra $^{+}$ & Simon et al. 1983 \\
\hline G. oxydans $621 \mathrm{H}$ & DSM 2343 & DSMZ \\
\hline \multicolumn{3}{|l|}{ Plasmid } \\
\hline pBBR1MCS-5 & Derivative of $\mathrm{pBBR} 1 \mathrm{MCS} ; \mathrm{Gm}^{\mathrm{R}}$ & Kovach et al. 1995 \\
\hline pBBR1MCS-2 & Derivative of pBBR1MCS; $\mathrm{Km}^{\mathrm{R}}$ & Kovach et al. 1995 \\
\hline pBBR1-tetall-strep_long & $\begin{array}{l}\text { Derivative of } \mathrm{pBBR} 1 \mathrm{MCS}-2 \text { with } t e t R-\mathrm{P}_{\text {tet }} \text { fragment from } \\
\text { E. coli } \mathrm{Tn} 10\end{array}$ & $\begin{array}{l}\text { Gift from Uwe Dep- } \\
\text { penmeier, Univer- } \\
\text { sity of Bonn }\end{array}$ \\
\hline pBBR1MCS-5-T ${ }_{g d h M}-$ MCS-T 0028 & $\begin{array}{l}\text { Derivative of pBBR1MCS-5 with terminator sequences } \\
\text { of GOX0265 }\left(\mathrm{T}_{\text {gdhM }}\right) \text { and GOX0028 }\left(\mathrm{T}_{0028}\right) \text { flanking the } \\
\text { multiple cloning site }\end{array}$ & This work \\
\hline $\mathrm{pBBR} 1 \mathrm{MCS}-5-\mathrm{T}_{g d h M^{-}}-t e t R-\mathrm{P}_{t e t}-m N G-\mathrm{T}_{\mathrm{BBa} \_\mathrm{B} 1002}-\mathrm{T}_{0028}$ & $\begin{array}{l}\text { Derivative of pBBR1MCS-5- } \mathrm{T}_{g d h M^{-}} \mathrm{MCS} \mathrm{T}_{0028} \text { carrying } \\
\text { fluorescent reporter gene } m N G \text { controlled by tetracycline- } \\
\text { induced promoter } \mathrm{P}_{\text {tet }} \text { and tet } R \text { encoding } \mathrm{P}_{t e t} \text { repressor } \\
\text { TetR }\end{array}$ & This work \\
\hline pBBR1MCS-5-tet $R-\mathrm{P}_{t e t}-m N G-\mathrm{T}_{\mathrm{BBa} \_} \mathrm{B} 1002-\mathrm{T}_{0028}$ & $\begin{array}{l}\text { Derivative of } \mathrm{pBBR} 1 \mathrm{MCS}-5-\mathrm{T}_{g d h M^{-}}-t e t R-\mathrm{P}_{t e t}-m N G- \\
\mathrm{T}_{\mathrm{BBa} B 1002}-\mathrm{T}_{0028} \text { lacking terminator } \mathrm{T}_{g d h M} \text { downstream } \\
\text { from } \text { tetR }\end{array}$ & This work \\
\hline pBBR1MCS-5- $\mathrm{T}_{g d h M^{-}}-t e t R-\mathrm{P}_{t e t}-m N G$ & $\begin{array}{l}\text { Derivative of } \mathrm{pBBR} 1 \mathrm{MCS}-5-\mathrm{T}_{g d h M^{-}} \text {tet } R-\mathrm{P}_{t e t}-m N G- \\
\mathrm{T}_{\mathrm{BBa} \_\mathrm{B} 1002}-\mathrm{T}_{0028} \text { lacking terminators } \mathrm{T}_{\mathrm{BBa} \_\mathrm{B} 1002} \text { and } \mathrm{T}_{0028} \\
\text { downstream from } m N G\end{array}$ & This work \\
\hline pBBR1MCS-5-tetR- $\mathrm{P}_{t e t}-m N G$ & $\begin{array}{l}\text { Derivative of } \mathrm{pBBR} 1 \mathrm{MCS}-5-\mathrm{T}_{g d h M^{-}}-t e t R-\mathrm{P}_{t e t}-m N G- \\
\mathrm{T}_{\mathrm{BBa} B \mathrm{~B} 1002}-\mathrm{T}_{0028} \text { lacking the terminators downstream from } \\
\text { tetR and } m N G\end{array}$ & This work \\
\hline 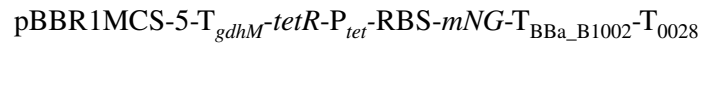 & $\begin{array}{l}\text { Derivative of pBBR1MCS-5-T } \mathrm{T}_{g d h M^{-}}-t e t R-\mathrm{P}_{t e t}-m N G- \\
\mathrm{T}_{\mathrm{BBa} B \mathrm{~B} 1002}-\mathrm{T}_{0028} \text { with ribosomal binding site AGGAGA } \\
\text { (Hentschel et al. 2013) inserted upstream from } m N G\end{array}$ & This work \\
\hline pBBR1MCS-5- $\mathrm{T}_{g d h M}-\mathrm{P}_{t e t}-m N G-\mathrm{T}_{\mathrm{BBa}}$ B $1002-\mathrm{T}_{0028}$ & $\begin{array}{l}\text { Derivative of pBBR1MCS-5- } \mathrm{T}_{g d h M^{-}} \text {tet } R-\mathrm{P}_{t e t}-m N G- \\
\mathrm{T}_{\mathrm{BBa} \_\mathrm{B} 1002}-\mathrm{T}_{0028} \text { lacking tet } R\end{array}$ & This work \\
\hline 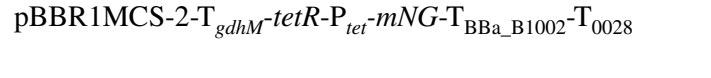 & $\begin{array}{l}\text { Derivative of pBBR1MCS-2 carrying } m N G \text { controlled by } \\
\mathrm{P}_{t e t} \text { and tet } R \text {, with each gene flanked by terminators }\end{array}$ & This work \\
\hline $\begin{array}{l}\text { pBBR1MCS-5-P } \mathrm{P}_{\text {lacI }} \text {-lacI- } \mathrm{P}_{\text {lacUV5 }}-\mathrm{RBS}-m N G- \\
\mathrm{T}_{\mathrm{BBa} \_B 1002}-\mathrm{T}_{0028}\end{array}$ & $\begin{array}{l}\text { Derivative of pBBR1MCS- } 5 \text { carrying } m N G \text { with RBS } \\
\text { AGGAGA controlled by IPTG-induced promoter } \mathrm{P}_{\text {lac } U V 5} \\
\text { and lacI encoding } \mathrm{P}_{\text {lac }} \text { rV5 } \\
\text { repressor LacI }\end{array}$ & This work \\
\hline pBBR1MCS-5-P $\mathrm{P}_{\text {lac } U v 5}-\mathrm{RBS}-m N G-\mathrm{T}_{\mathrm{BBa} \_\mathrm{B} 1002}-\mathrm{T}_{0028}$ & $\begin{array}{l}\text { Derivative of pBBR1MCS-5- } \mathrm{P}_{\text {lac }} \text {-lacI- } \mathrm{P}_{\text {lac } U v 5}-\mathrm{RBS}-m N G \text { - } \\
\text { tBBa-t } 28 \text { lacking lacI }\end{array}$ & This work \\
\hline $\begin{array}{l}\text { pBBR1MCS-5-lacI-P } \mathrm{P}_{\text {lac I }}-\mathrm{P}_{\text {lac UV5 }}-\mathrm{RBS}-m N G- \\
\mathrm{T}_{\mathrm{BBa} \_\mathrm{B} 1002}-\mathrm{T}_{0028}\end{array}$ & 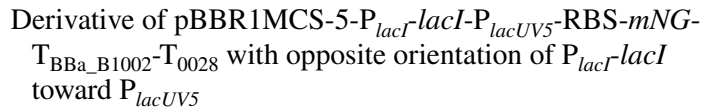 & This work \\
\hline
\end{tabular}

the conditions recommended by the manufacturer (New England Biolabs). Unless stated otherwise for the construction of all reporter plasmids, amplified DNA fragments were integrated in the restricted broad-host vector pBBR1MCS-5 in a one-step isothermal Gibson assembly $\left(50{ }^{\circ} \mathrm{C}, 1 \mathrm{~h}\right)$ (Gibson et al. 2009). All cloning steps to obtain desired plasmids were conducted in $E$. coli S17-1 and plasmids were isolated using a QIAprep spin miniprep kit (Qiagen). Inserts of all constructed plasmids were checked for correctness by DNA sequencing (Eurofins MWG).

\section{Construction of plasmids}

For the construction of plasmids, the empty vector pBBR1MCS-5-T ${ }_{g d h M}$-MCS-T 0028 was generated from pBBR1MCS-5. It carries the terminator sequences of GOX0265 $\left(\mathrm{T}_{g d h M}\right)$ and GOX0028 $\left(\mathrm{T}_{0028}\right)$ flanking the multiple cloning site (MCS) to minimize interfering effects between the plasmid backbone and expression of the inserted genes.

Plasmid pBBR1MCS-5-T $g d h M^{-}$tet $R-\mathrm{P}_{t e t}-m N G-$ $\mathrm{T}_{\mathrm{BBa} \_\mathrm{B} 1002}-\mathrm{T}_{0028}$ was constructed using the primer pair 
$\mathrm{PF} 1 / \mathrm{PF} 2$ to generate a 763 bp DNA fragment with tet $R$ $\mathrm{P}_{\text {tet }}$ from plasmid pBBR1-tetall-strep_long and primer pair PF3/PF4 to generate a 802 bp DNA fragment with $m N G$ and the terminator BBa_B1002 from the iGEM parts library from pBBR1MCS-5-araC- $\mathrm{P}_{B A D^{-}} m N G$ (Fricke et al. 2020). For insertion of the two DNA fragments

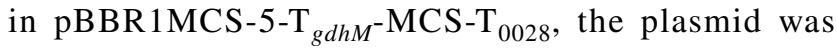
restricted with $X b a \mathrm{I}$ and $E c o$ RI.

Plasmid pBBR1MCS-5-tet $R-\mathrm{P}_{t e t}-m N G-\mathrm{T}_{\mathrm{BBa} \_B 1002}-\mathrm{T}_{0028}$ lacking terminator $\mathrm{T}_{g d h M}$ downstream from tet $R$ was constructed by amplification of a $576 \mathrm{bp}$ DNA fragment from pBBR1MCS-5- $\mathrm{T}_{g d h M^{-}}-t e t R-\mathrm{P}_{t e t}-m N G-\mathrm{T}_{\mathrm{BBa}}{ }_{1002}-\mathrm{T}_{0028}$ with primer pair PF5/PF6 and ligated with Eco81I/MunIdigested pBBR1MCS-5-T $\mathrm{T}_{g d h M^{-}}$tet $R-\mathrm{P}_{t e t}-m N G$ $\mathrm{T}_{\mathrm{BBa} \_ \text {B } 1002}-\mathrm{T}_{0028}$ replacing $\mathrm{T}_{\text {gdh }}$-tet $R$ by tet $R$ only.

For the construction of pBBR1MCS-5-T $\mathrm{T}_{g d h M^{-}}$tet $R-\mathrm{P}_{\text {tet }}{ }^{-}$ $m N G$ lacking the terminators $\mathrm{T}_{\mathrm{BBa} \_1002}$ and $\mathrm{T}_{0028}$ downstream from $m N G$, the primer pairs PF7/PF8 and PF9/ PF10 were used to amplify a $1,471 \mathrm{bp}$ DNA fragment comprising $t e t R-\mathrm{P}_{t e t}-m N G$ and a 643 bp DNA fragment comprising a part of the pBBR1MCS-5 backbone using pBBR1MCS-5-T $\mathrm{T}_{g d h M^{-}}$tet $R-\mathrm{P}_{t e t}-m N G-\mathrm{T}_{\mathrm{BBa} \_\mathrm{B} 1002}-\mathrm{T}_{0028}$ as a template. Both DNA fragments were ligated with $\mathrm{Xba \textrm {I }} /$ Bsp1407I-digested pBBR1MCS-5-T gdhM $-\mathrm{MCS}^{\mathrm{T}} \mathrm{T}_{0028}$.

The plasmid pBBR1MCS-5-tet $R-\mathrm{P}_{\text {tet }}-m N G$ lacking all terminators downstream from tet $R$ and $m N G$ was generated by removing $\mathrm{T}_{g d h M}$ from $\mathrm{pBBR} 1 \mathrm{MCS}$ $5-\mathrm{T}_{g d h M^{-}}$tet $R-\mathrm{P}_{\text {tet }}-m N G$ with primer pair $\mathrm{PF}$ /PF6 as described above for the removal of $\mathrm{T}_{g d h M}$ from pBBR1MCS-5- $\mathrm{T}_{g d h M^{-}}-t e t R-\mathrm{P}_{t e t}-m N G-\mathrm{T}_{\text {BBa_B } 1002}-\mathrm{T}_{0028}$.

In another construct, for comparing and enhancing resulting reporter protein level when using the $\mathrm{P}_{\text {tet }}$ region including its native ribosome binding site $\left(\mathrm{RBS}_{\text {Ptet }}\right)$ in $G$. oxydans, the RBS AGGAGA $\left(\mathrm{RBS}_{\mathrm{AGGAGA}}\right)$, functional and strong in G. oxydans, was inserted upstream from $m N G$ (Fricke et al. 2020; Hentschel et al. 2013). Therefore, the DNA fragments tet $R-\mathrm{P}_{\text {tet }}$-RBS (761 bp) and RBS- $m N G(811 \mathrm{bp})$ were amplified with the primer pairs PF1/PF12 and PF13/

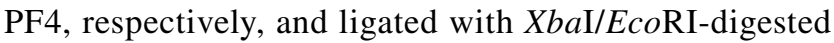

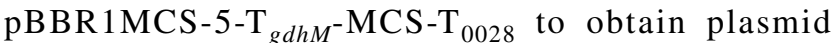
pBBR1MCS-5-T $\mathrm{T}_{g d h M^{-}}-t e t R-\mathrm{P}_{t e t}-\mathrm{RBS}-m N G-\mathrm{T}_{\mathrm{BB} \_\mathrm{B} 1002}-\mathrm{T}_{0028}$.

For plasmid pBBR1MCS-5-T ${ }_{g d h M^{-}} \mathrm{P}_{t e t}-m N G-$ $\mathrm{T}_{\mathrm{BBa} \_\mathrm{B} 1002}-\mathrm{T}_{0028}$ lacking tetR, fragment $\mathrm{P}_{\text {tet }}-m N G$ (901 bp) was amplified from pBBR1MCS-5-T $\mathrm{T}_{g d h M^{-}}$tet $R-\mathrm{P}_{t e t}-m N G-$ $\mathrm{T}_{\mathrm{BBa} B 1002}-\mathrm{T}_{0028}$ with primer pair PF11/PF4 and ligated with XbaI / EcoRI-digested pBBR1MCS-5-T gdhM $^{-\mathrm{MCS}-\mathrm{T}_{0028}}$.

To change the plasmid backbone from pBBR1MCS-5 to $\mathrm{pBBR} 1 \mathrm{MCS}-2$ and create pBBR1MCS-2-T ${ }_{g d h M^{-}}$ tet $R-\mathrm{P}_{t e t}-m N G-\mathrm{T}_{\mathrm{BBa} B} \mathrm{~B} 1002-\mathrm{T}_{0028}$, the DNA fragment with $\mathrm{T}_{g d h M^{-}} t e t R-\mathrm{P}_{t e t}-m N G-\mathrm{T}_{\mathrm{BBa} B} \mathrm{~B}_{1002}-\mathrm{T}_{0028}$ was excised from pBBR1MCS-5- $\mathrm{T}_{g d h M^{-}}$tet $R-\mathrm{P}_{t e t}-m N G-\mathrm{T}_{\mathrm{BBa}} \mathrm{B} 1002-\mathrm{T}_{0028}$ and ligated with $\mathrm{SacI} / \mathrm{XhoI}$-digested pBBR1MCS-2.
The plasmid pBBR1MCS-5-P $\mathrm{P}_{\text {lacI }}$-lacI-P $\mathrm{P}_{\text {lac UV5 }}$-RBS$m N G-\mathrm{T}_{\mathrm{BBa} \_} \mathrm{B} 1002 \mathrm{~T}_{0028}$ was constructed by ligating the

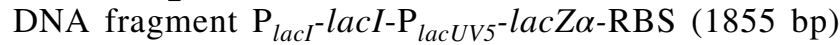
and $m N G-\mathrm{T}_{\text {BBa_B1002 }}-\mathrm{T}_{0028}(954 \mathrm{bp})$ with $B s h \mathrm{TI} / S p h \mathrm{I}-$ digested pBBR1MCS-5. Here, upstream from $m N G$ the RBS AGGAGA known to be functional in G. oxydans was integrated into the construct (Hentschel et al. 2013). The DNA sequence of $\mathrm{P}_{\text {lacl }}$-lacI- $\mathrm{P}_{\text {lac Uv5 }}$-lacZ $\alpha$ was derived from E. coli BL21 and obtained with primer pair PF14/ PF15 and plasmid pK18mobsacB-DE3 (Kortmann et al. $2015)$. The DNA fragment $m N G-\mathrm{T}_{\mathrm{BBa}} \mathrm{B} 1002-\mathrm{T}_{0028}$ was amplified with primer pair PF16/PF17 from plasmid pBBR1MCS-5- $\mathrm{T}_{g d h M^{-}}-t e t R-\mathrm{P}_{t e t}-m N G-\mathrm{T}_{\mathrm{BBa} \_\mathrm{B} 1002}-\mathrm{T}_{0028}$.

For the construction of plasmid pBBR1MCS-5-P lacUV5 $^{-}$ RBS- $m N G-\mathrm{T}_{\mathrm{BBa} \_\mathrm{B} 1002}-\mathrm{T}_{0028}$ lacking the repressor gene lacI, the DNA fragment $\mathrm{P}_{\text {lacUVV }}-\mathrm{RBS}-m N G-\mathrm{T}_{\mathrm{BBa} \_\mathrm{B} 1002}-\mathrm{T}_{0028}$ (1575 bp) was amplified with primer pair PF18/PF17 from pBBR1MCS-5-P lac $_{\text {lacI-P }}$ lacUV5 5 -RBS- $m N G-\mathrm{T}_{\mathrm{BBa} B \mathrm{~B} 1002}-\mathrm{T}_{0028}$ and ligated with $B s h \mathrm{TI} / S p h \mathrm{I}$-digested pBBR1MCS-5.

The plasmid pBBR1MCS-5-lacI- $\mathrm{P}_{\text {lacI }} \mathrm{P}_{\text {lac Uv5 }}$-RBS- $m N G$ $\mathrm{T}_{\mathrm{BBa} \_\mathrm{B} 1002}-\mathrm{T}_{0028}$ with $\mathrm{P}_{\text {lacl }}$ lacI in the opposite orientation to $\mathrm{P}_{\text {lac } U V 5}-m N G$ was constructed by amplification of the DNA fragments $\mathrm{P}_{\text {lac }}$ lacI (1,261 bp) with the primer pair PF19/ PF20 and $\mathrm{P}_{\text {lac UV5 }}-m N G-\mathrm{T}_{\text {BBa_B1002 }}-\mathrm{T}_{0028}(1556 \mathrm{bp})$ with the primer pair PF21/PF17. Both fragments were ligated into pBBR1MCS-5 digested with BshTI and SphI.

\section{Measurements of mNG fluorescence}

Expression of promoter-reporter constructs in G. oxydans was monitored using the fluorescence protein $\mathrm{mNeonGreen}$ (mNG) as a reporter (Shaner et al. 2013). In shake flask experiments, the inducibility of $\mathrm{P}_{t e t}$-derived $m N G$ expression in $G$. oxydans was tested by the addition of $200 \mathrm{ng} \mathrm{mL}^{-1}$ anhydrotetracycline (ATc) from a $0.2 \mathrm{mg} \mathrm{mL}^{-1}$ stock solution in 50\% ethanol. Non-induced reference cultures were supplemented with an equal volume of $50 \%$ ethanol. For experiments with $\mathrm{P}_{\text {lac UVV }}$-controlled $m N G$ expression, $1 \mathrm{mM}$ of isopropyl- $\beta$-D-1-thiogalactopyranoside (IPTG) was supplemented from a $100 \mathrm{mM}$ stock solution in water. An equal volume of water was added to non-induced reference cultures. Throughout the cultivation samples were taken to monitor growth $\left(\mathrm{OD}_{600}\right)$ by a spectrophotometer (UV-1800, Shimadzu) and fluorescence emission using an Infinite M1000 PRO Tecan reader $\left(\lambda_{\text {ex }} 504 \mathrm{~nm} / \lambda_{\text {em }} 517 \mathrm{~nm}\right.$, gain 60 , ex/em bandwidth $5 \mathrm{~nm}$, infinite M1000 PRO Tecan). Using a BioLector system, $800 \mu \mathrm{L}$ batches of D-mannitol medium were inoculated from overnight starter cultures to an initial $\mathrm{OD}_{600}$ of 0.3 and incubated at $30{ }^{\circ} \mathrm{C}(1,200 \mathrm{rpm} ; 85 \%$ humidity) using 48-well Flowerplates ${ }^{\circledR}$ (m2p-labs). Backscattering light intensity $\left(\mathrm{A}_{620 \mathrm{~nm}}\right)$ for growth and fluorescence emission $\left(\lambda_{\mathrm{ex}} 510 \mathrm{~nm} / \lambda_{\mathrm{em}} 532 \mathrm{~nm}\right)$ were monitored online during the cultivation. Backscatter and fluorescence 
signals were measured using gain 15 or 20 and 50 or 60 , respectively, as indicated in the figure legends. Fluorescence values that did not exceed the emission signals from cell-free control samples were set to 1 . Specific fluorescence was calculated by taking the quotient of the fluorescence signal per biomass value at a given time point. Specific fluorescence values lower than in the cell-free control samples were set to 0.01 . All data presented in the same graphs were obtained in the same BioLector growth experiment using identical gains.

\section{Cell flow cytometer analysis}

Reporter gene expression was analyzed by measuring $\mathrm{mNG}$ fluorescence on the single cell level with $G$. oxydans $621 \mathrm{H}$ either carrying the plasmid pBBR1MCS-5- $\mathrm{T}_{g d h M^{-}} t e t R-\mathrm{P}_{t e t}{ }^{-}$ $m N G-\mathrm{T}_{\mathrm{BBa} \_\mathrm{B} 1002}-\mathrm{T}_{0028}, \mathrm{pBBR} 1 \mathrm{MCS}-2-\mathrm{T}_{\text {gdh }}$-tet $R-\mathrm{P}_{t e t}-m N G-$ $\mathrm{T}_{\mathrm{BBa} \_\mathrm{B} 1002}-\mathrm{T}_{0028}$, or pBBR1MCS-5- $\mathrm{P}_{\text {lacl }}$-lacI- $\mathrm{P}_{\text {lacUV5 }}$-RBS$m N G-\mathrm{T}_{\mathrm{BBa}_{\mathrm{B}} 1002} \mathrm{~T}_{0028}$ using a FACSAria ${ }^{\mathrm{TM}}$ Fusion cell sorter (BD Biosciences) run with 70 psi sheath pressure and equipped with a $70 \mu \mathrm{m}$ nozzle. Data acquisition and analysis of the flow cytometer was controlled by the FACSDiva 8.0.3 software (BD Biosciences). Using a 488-nm solid blue laser beam, the forward scatter (FSC) and side scatter (SSC) were employed for cell analysis. Particles/events with FSC-H and SSC-H signals below a threshold of 200 a.u. and 300 a.u. were excluded from the analysis. Detection of emitted $\mathrm{mNG}$ fluorescence from the SSC signal was performed by combining a 502-nm long-pass and 530/30-nm band-pass filter. The entire cell population was analyzed in a three-step gating strategy. Initially, the assessed cell population was gated in a FSC-H $v s$. SSC-H plot, to exclude signals originating from electronic noise and cell debris. From the resulting population, the FSC-H signal was plotted against the FSC-W signal. Subsequently, the obtained population was gated in a SSC-H vs. SSC-W plot, to ensure singlet discrimination. The gated singlet population was used for fluorescence acquisition in all experiments (fluorescence intensity $v s$. cell count). For all samples, 100,000 events were recorded with an event rate below 10,000 events/s. FlowJo 10.7.2 for Windows (FlowJo, LLC) was used for data analysis and visualization of all gated events $(n=100,000)$.

\section{Fluorescence microscopy}

For fluorescence microscopy, cells were placed on agarose-coated microscope slides and covered by a coverslip. Images were taken on a Zeiss AxioImager M2 imaging microscope that was equipped with a Plan-Apochromat $100 \times / 1.40$-numerical aperture phase-contrast oil-immersion objective and an AxioCam MRm camera. Fluorescence was measured using the $46 \mathrm{HE}$ filter set $\left(\lambda_{\mathrm{ex}} 500 / 20 \mathrm{~nm} / \lambda_{\mathrm{em}}\right.$ $535 / 30 \mathrm{~nm}$ ). For all images, identical exposure times were applied. Digital images were acquired and analyzed with AxioVision Rel. 4.8 software (Zeiss).

\section{Total DNA extraction, library preparation, Illumina sequencing, and data analysis}

Total DNA was purified from a culture aliquot using a NucleoSpin Microbial DNA Mini kit (MACHEREY-NAGEL). DNA concentrations were measured using a Qubit 2.0 fluorometer (Thermo Fisher Scientific). Illumina sequencing libraries of $t e t R-\mathrm{P}_{\text {tet }}$ and lacI- $\mathrm{P}_{\text {lacUV5 }}$ samples were prepared from $1 \mu \mathrm{g}$ of isolated DNA using the NEBNext Ultra ${ }^{\mathrm{TM}}$ II DNA Library Prep Kit for Illumina according to the manufacturers' instructions (NEB). The libraries were evaluated by qPCR using the KAPA library quantification kit (Peqlab) and then normalized for sample pooling. Pairedend sequencing with a read length of $2 \times 150$ bases was performed in-house on an Illumina MiSeq system. The demultiplexed sequencing output (base calls) was obtained as fastq files and used for trimming and quality filtering, mapping, and coverage calculation using the CLC Genomics Workbench software (Qiagen). For the mappings, the improved genome sequence from G. oxydans $621 \mathrm{H}$ and the $t e t R-\mathrm{P}_{\text {tet }}$ or lacI- $\mathrm{P}_{\text {lac UV5 }}$ plasmid sequence was used (Kranz et al. 2017).

\section{Computational methods}

Homology modeling of TetR, LacI, and AraC structures was performed by YASARA Structure version 19.12.14 (Krieger et al. 2002) using the default settings (PSI-BLAST iterations: 6 , E value cutoff: 0.5, templates: 5), and with oligomerization state adjusted to 2 for TetR and AraC, and to 4 for LacI (Altschul et al. 1997). A position-specific scoring matrix (PSSM) was used to score the obtained template structures (Jones 1999; Qiu and Elber 2006). The obtained hybrid models were further evaluated for protein geometry by VERIFY3D and ProSA (Eisenberg et al. 1997; Sippl 1993). Operator models of tetO and $\mathrm{AraI}_{1}$ were generated with Avogadro as B-shaped DNA (Hanwell et al. 2012). The initial coordinates for $l a c O$ were taken from the $\mathrm{X}$-ray structure (PDB ID 1EFA, resolution 2.6 $⿱$ ) (Bell and Lewis 2000).

Surface residues were determined with PyMol script (default cutoff of $2.5 \AA^{2}$ ). The protonation states of titratable residues were assigned on the basis of $\mathrm{pK}_{\mathrm{a}}$ values obtained from the PROPKA 3.1 program for the $\mathrm{pH}$ values 7, 6, 5, and 4 (Olsson et al. 2011).

Modeling protein-protein and protein-DNA complexes was performed by using the HADDOCK Webserver (van Zundert et al. 2016). To understand the DNA binding behavior, protein-DNA docking simulations of the transcription factors and their respective operator sequence were done. In docking simulations, a dimeric model for TetR and LacI 
and a monomeric model for AraC were used. The charge states of proteins were adjusted to the respective $\mathrm{pH}$ based on the previous $\mathrm{pK}_{\mathrm{a}}$ calculations and were adjusted to the respective $\mathrm{pH}$ either directly within the PDB file according to the HADDOCK specifications (Asp, Glu), or within the HADDOCK interface (His). Oligomerization of proteins was computed by performing protein-protein docking with the transcription factor subunits, i.e., monomer-monomer docking for TetR and AraC, and dimer-dimer docking for LacI. Due to the fact that the LacI homology model was missing the second tetramerization helix, the dimer structure taken from the crystal structure (PDB ID 3EDC, resolution $2.10 \AA$ ) was used for the LacI tetramerization modeling (Stenberg and Vihinen 2009).

\section{Results}

\section{A pBBR1MCS-5-based TetR-P $P_{\text {tet }}$ System was very tight and highly inducible and tunable}

The tet $R$ - $\mathrm{P}_{\text {tet }}$ region including its native RBS from transposon Tn 10 was used to construct a pBBR1MCS-5-based reporter plasmid using the reporter gene mNeonGreen $(m N G)$. The tetR gene under the control of its native promoter $\mathrm{P}_{t e t R}$ overlapping with the divergently oriented TetR-dependent promoter $\mathrm{P}_{t e t}$ followed by $m N G$ were integrated into the MCS of pBBR1MCS-5-T ${ }_{g d h M}$-MCS- $\mathrm{T}_{0028}$ as described in Material and Methods. DNA sequences for transcription terminators were placed adjacent to the $t e t R-\mathrm{P}_{t e t}-m N G$ insert to create transcriptional barriers between the genetic elements on the insert and on the plasmid backbone.

The leakiness and inducibility of $\mathrm{P}_{t e t}$ were tested in G. oxydans $621 \mathrm{H}$ harboring the plasmid pBBR1MCS$5-\mathrm{T}_{g d h M^{-}}-t e t R-\mathrm{P}_{t e t}-m N G-\mathrm{T}_{\mathrm{BBa}_{-} \mathrm{B} 1002}-\mathrm{T}_{0028}$ by omitting and adding anhydrotetracycline (ATc). A pre-culture was split and used to inoculate shake flasks for growth in D-mannitol medium without and with $200 \mathrm{ng} \mathrm{mL}^{-1}$ ATc. The highest $\mathrm{mNG}$ fluorescence signals were measured in induced cultures after $10 \mathrm{~h}$ of growth at the end of the exponential growth phase, followed by a slight decrease in the stationary phase (Fig. 1a). In the non-induced cultures, the $\mathrm{mNG}$ signals barely surpassed background signals of cell-free control samples, suggesting very tight repression of $\mathrm{P}_{\text {tet }}$ in the absence of inducer. Based on the absolute and the specific $\mathrm{mNG}$ fluorescence, the maximal induction ratios were calculated to be $2284 \pm 263$-fold and $2661 \pm 180$-fold, respectively. At the end of the cultivation $(24 \mathrm{~h})$, cells of an induced culture were harvested and total DNA was purified for Illumina sequencing. In the read data analysis, $99.5 \%$ of the reads mapped to the updated reference sequences of the $G$. oxydans $621 \mathrm{H}$ genome, the 5 endogenous plasmids, and the $\mathrm{mNG}$ expression plasmid with tet $R-\mathrm{P}_{\text {tet }}$ (Kranz et al. 2017). Thus, the sequencing results excluded undesired contaminations and verified that the $\mathrm{P}_{t e t}$-derived $m N G$ expression was highly induced in G. $o x y$ dans $621 \mathrm{H}$ carrying the plasmid pBBR1MCS-5-T ${ }_{g d h M^{-}}$ tet $R-\mathrm{P}_{\text {tet }}-m N G-\mathrm{T}_{\mathrm{BBa} \_\mathrm{B} 1002}-\mathrm{T}_{0028}$. In microscale BioLector cultivations a similar induction profile of $\mathrm{P}_{t e t}$ was observed as in shake flasks. The fluorescence in ATc-supplemented cultures peaked approximately after $8 \mathrm{~h}$ also followed by a decreased fluorescence level in the stationary phase (Fig. 1b). Again, the basal expression under non-induced conditions was barely detectable and the maximal induction ratio based on the specific fluorescence was calculated to be $3674 \pm 193$-fold. The drop in $\mathrm{mNG}$ fluorescence signals observed in shake flasks and in BioLector cultivations in the stationary phase was caused by the decreased $\mathrm{pH}$ of the medium ( $\mathrm{pH} 4.6)$ and could be largely recovered at pH 6 as outlined below and described previously (Fricke et al. 2020).

To verify that TetR is responsible for the repression of $\mathrm{P}_{\text {tet }}$ also in G. oxydans, we constructed the plasmid pBBR1MCS-5- $\mathrm{T}_{g d h M}-\mathrm{P}_{t e t}-m N G-\mathrm{T}_{\mathrm{BBa} \_\mathrm{B} 1002}-\mathrm{T}_{0028}$ lacking the tetR gene. In the absence of the plasmid-encoded regulator TetR, in both conditions with ATc supplement and without, the $m N G$ expression from $\mathrm{P}_{t e t}$ was even higher than in the induced control cultures containing the tetR gene on the plasmid (Fig. S1). This indicated that in G. oxydans $\mathrm{P}_{\text {tet }}$ is also fully repressed by TetR like in $E$. coli and that nonblocked $\mathrm{P}_{\text {tet }}$ is highly active in G. oxydans. Interestingly, even without the tet $R$ gene the addition of ATc resulted in a higher maximal specific fluorescence $(28.8 \pm 1.3$ a.u.) than without ATc $(23.5 \pm 1.9$ a.u). This suggested that in $G$. oxydans the $\mathrm{P}_{\text {tet }}$ activity could additionally be affected by an endogenous factor.

We then tested the tunability of the TetR- $\mathrm{P}_{t e t}$ system in G. oxydans by varying the ATc concentration from 10 to $400 \mathrm{ng} \mathrm{mL}{ }^{-1}$. Gradual increase of the inducer concentration led to a gradual increase in $\mathrm{mNG}$ fluorescence illustrating the high dynamic range of $\mathrm{P}_{t e t}$-derived gene expression in G. oxydans with the pBBR1MCS-5 backbone (Fig. 1c). Comparing the peaking fluorescence signals, the system appeared to be almost fully induced with 150 to $200 \mathrm{ng} \mathrm{mL}^{-1}$ ATc. According to flow cytometry analysis (FACS) of samples taken $7 \mathrm{~h}$ after induction (Fig. 1a), in both ATc-induced and non-supplemented cultures high population homogeneity was observed (Fig. 1d). Ninety-five percent and $94 \%$ of the cells of a sample were found to exhibit either very low ( 400 a.u., non-induced) or very high $(\sim 80,000$ a.u., ATc-induced) $\mathrm{mNG}$ fluorescence signals. To visualize this high homogeneity by microscopy, images of induced and non-induced $G$. oxydans cells harboring the plasmid pBBR1MCS-5- $\mathrm{T}_{g d h M^{-}}$tet $R-\mathrm{P}_{t e t}-m N G-\mathrm{T}_{\mathrm{BBa} \_\mathrm{B} 1002}-\mathrm{T}_{0028}$ were taken (Fig. S2). In accordance with the data obtained by flow cytometry, the microscopic images confirmed the 
a

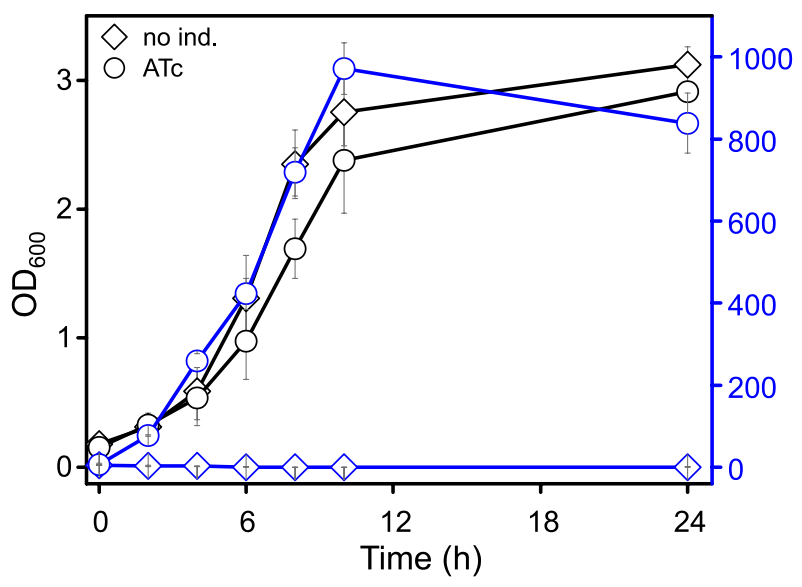

C

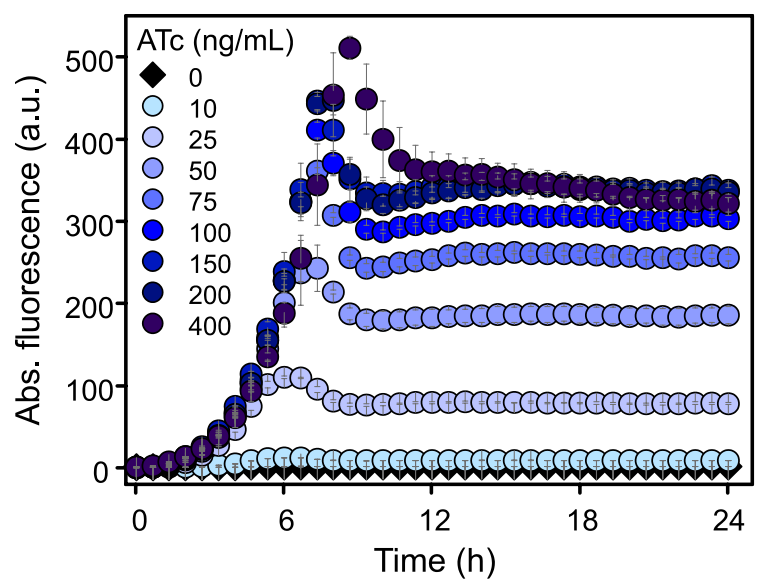

Fig. 1 Performance of the TetR-P $\mathrm{P}_{\text {tet }}$ system in G. oxydans $621 \mathrm{H}$. a Growth $\left(\mathrm{OD}_{600}\right)$ and specific $\mathrm{mNG}$ fluorescence in $G$. oxydans $621 \mathrm{H}$ carrying plasmid pBBR1MCS-5- $\mathrm{T}_{\text {gdh }}-t e t R-\mathrm{P}_{\text {tet }}-m N G-$ $\mathrm{T}_{\mathrm{BBa} B 1002}-\mathrm{T}_{0028}$ in ATc-induced $\left(200 \mathrm{ng} \mathrm{mL}^{-1}\right)$ and non-induced condition in shake flasks. The $\mathrm{mNG}$ fluorescence was measured in a Tecan reader (gain 60). The specific fluorescence was calculated from absolute fluorescence per $\mathrm{OD}_{600}$. Data represent mean values and standard deviation from three biological replicates with three technical replicates each. b Growth according to backscatter (gain 15) and specific $\mathrm{mNG}$ fluorescence (with gain 50) of G. oxydans $621 \mathrm{H}$ carrying plasmid pBBR1MCS-5-T $\mathrm{T}_{\text {dh }}$-tet $R-\mathrm{P}_{t e t}-m N G-\mathrm{T}_{\mathrm{BBa} \_\mathrm{B} 1002}-\mathrm{T}_{0028}$

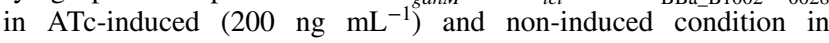
microscale BioLector cultivations. Data represent mean values and b

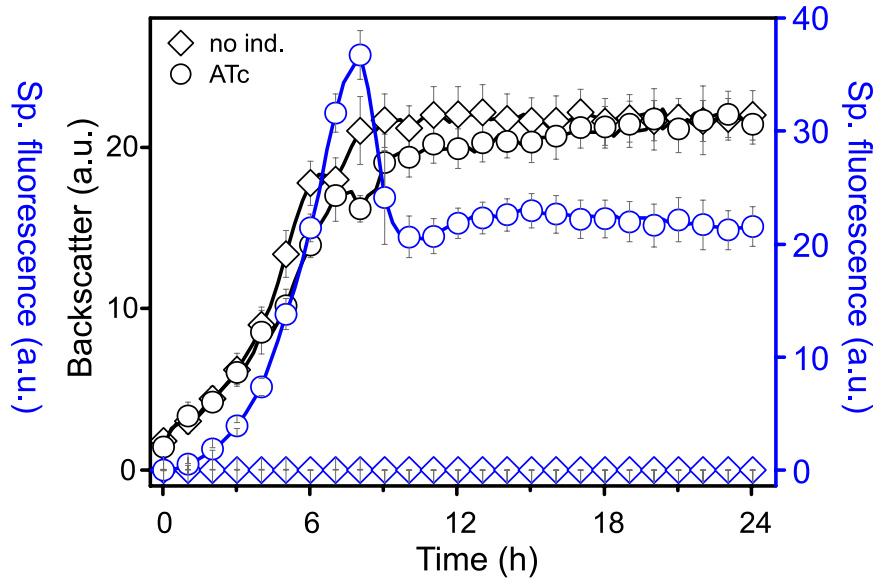

d

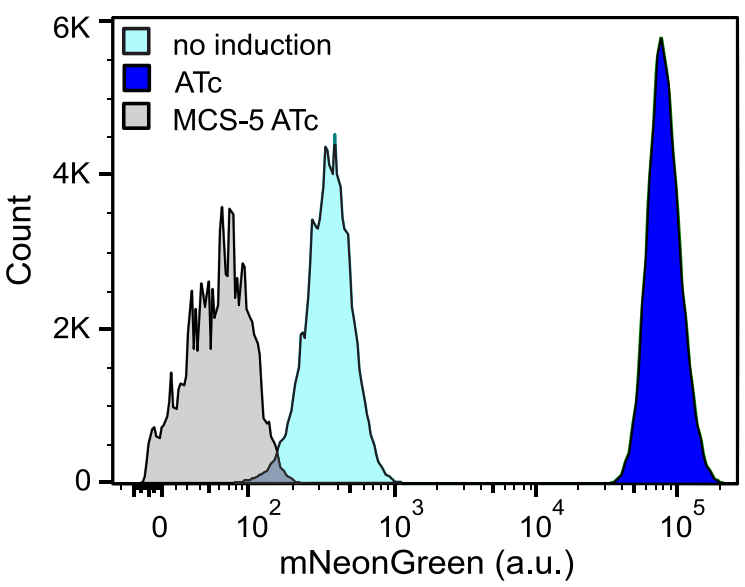

standard deviation from four biological replicates with three technical replicates each. c Graded ATc-dependent $m N G$ expression in G. oxydans $621 \mathrm{H}$ carrying plasmid pBBR1MCS-5-T gdh $^{-t e t R}-\mathrm{P}_{\text {tet }}{ }^{-}$ $m N G-\mathrm{T}_{\mathrm{BBa} \_\mathrm{B} 1002}-\mathrm{T}_{0028}$ in microscale BioLector cultivations. Reporter gene expression measured as fluorescence (gain 50) was induced with increasing concentrations of ATc from 10 to $400 \mathrm{ng} \mathrm{mL}^{-1}$ as indicated. d FACS analysis of $G$. oxydans $621 \mathrm{H}$ carrying plasmid

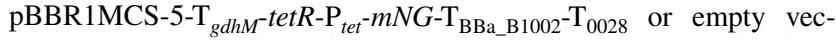
tor pBBR1MCS-5 (MCS-5) as a control. Cells were grown in shake flasks with D-mannitol medium without and with $200 \mathrm{ng} \mathrm{mL}^{-1}$ ATc. FACS analysis was performed $7 \mathrm{~h}$ after inoculation/induction. Total counts per sample represent 100.000 events strong inducibility of pBBR1MCS-5-based TetR-P $\mathrm{P}_{t e t}$ and the highly homogenous induction response in $G$. oxydans.

During growth, the G. oxydans D-mannitol medium initially set to $\mathrm{pH} 6$ is acidified to $\mathrm{pH} 4.7$ which causes a loss of intracellular $\mathrm{mNG}$ fluorescence suggesting a decreased cytoplasmic $\mathrm{pH}$, at least in the stationary phase (Fricke et al. 2020). We wanted to test experimentally whether an already initially lower medium $\mathrm{pH}$ could result in leakiness of $\mathrm{P}_{t e t}$ in G. oxydans already during growth as observed in Komagataeibacter (Florea et al. 2016). Therefore, G. oxydans carrying the plasmid pBBR1MCS-5- $\mathrm{T}_{g d h M^{-}}$tet $R-\mathrm{P}_{\text {tet }}{ }^{-}$ $m N G-\mathrm{T}_{\mathrm{BBa} \_\mathrm{B} 1002} \mathrm{~T}_{0028}$ was grown in D-mannitol medium initially adjusted to $\mathrm{pH} 6,5,4$ and 3 both in the absence and presence of ATc. After $23 \mathrm{~h}$ cells were centrifuged and resuspended in fresh D-mannitol-free medium set to $\mathrm{pH} 6$ to check for potential $\mathrm{pH}$-dependent recovery of 
$\mathrm{mNG}$ fluorescence above the respective levels monitored before that would indicate a leakiness of $\mathrm{P}_{t e t}$ together with a loss of $\mathrm{mNG}$ fluorescence during growth. In all noninduced cultures, very low maximal fluorescence signals $(0.6 \pm 0.1$ to $1.3 \pm 0.2$ a.u. $)$ were measured independent of the initial medium $\mathrm{pH}$ (Fig. S3a-b). Cells grown in $\mathrm{pH} 3$ exhibited the lowest signals and a different growth according to backscatter compared to all other cultures. No sufficient increase of $\mathrm{mNG}$ fluorescence was observed in any non-induced condition in the exponential growth phase to suggest a leakiness of $\mathrm{P}_{t e t}$ in G. oxydans. Moreover, after transfer $(23 \mathrm{~h})$ of the cells into fresh D-mannitol-free medium adjusted to $\mathrm{pH} 6$ no recovery of $\mathrm{mNG}$ fluorescence above the levels before could be observed. Thus, since the strong induction of $\mathrm{P}_{t e t}$ by ATc in the cells grown in each medium of this $\mathrm{pH}$ series indicated that the $\mathrm{mNG}$ protein could always be produced during the exponential phase of growth and exhibited strong fluorescence property (Fig. S3c-d), the results together indicated that expression from $\mathrm{P}_{t e t}$ was really tightly repressed in $G$. oxydans in all $\mathrm{pH}$ conditions, even in medium initially set to $\mathrm{pH} 3$.

\section{Terminators strongly affected $\mathrm{mNG}$ expression strength but not repression of $P_{\text {tet }}$}

Since we did not observe and could not show leakiness of the TetR-P $\mathrm{P}_{\text {tet }}$ system in growing G. oxydans cells per se or in dependence of the medium $\mathrm{pH}$, we wanted to analyze the influence of terminator sequences on the functionality and leakiness of the TetR- $\mathrm{P}_{t e t}$ system. Therefore, we constructed plasmids lacking terminators downstream from tet $R$ or $m N G$ and both and compared these constructs in regard to $\mathrm{P}_{t e t}$-derived $m N G$ expression in G. oxydans (Fig. 2). The terminators downstream from $m N G$ had a major influence on the resulting $\mathrm{mNG}$ fluorescence level. With plasmid pBBR1MCS-5- $\mathrm{T}_{g d h M^{-}}$tet $R-\mathrm{P}_{t e t}-m N G$ not having $\mathrm{T}_{\mathrm{BBa} \_\mathrm{B} 1002}$ and $\mathrm{T}_{0028}$ downstream from $m N G$, the $\mathrm{mNG}$ fluorescence signals were reduced by half in ATc-induced $G$. oxydans cells. Compared to the reference plasmid including all terminators, the maximum in specific fluorescence dropped from $19.4 \pm 2.9$ a.u. to $10.5 \pm 0.2$ a.u. (Fig. 2 e). The specific fluorescence signals of $G$. oxydans harboring the plasmid pBBR1MCS-5-tetR-P $\mathrm{P}_{t e t}-m N G-\mathrm{T}_{\mathrm{BBa} \_B 1002}-\mathrm{T}_{0028}$ lacking $\mathrm{T}_{g d h M}$ downstream from tet $R$ were significantly ( $p=0.0383)$ higher $(22.3 \pm 1.1$ a.u.) compared to the reference $(19.4 \pm 2.9$ a.u. $)$ suggesting a little positive effect on $\mathrm{P}_{t e t}$-derived induction and expression strength when $\mathrm{T}_{g d h M}$ downstream from tet $R$ was absent. The construct pBBR1MCS-5-tetR-P $\mathrm{P}_{t e t}-m N G$ lacking all terminators performed similar $(9.5 \pm 0.7$ a.u. $)$ as pBBR1MCS-5- $\mathrm{T}_{g d h M^{-}}$tet $R-\mathrm{P}_{t e t}-m N G$ lacking only the terminators downstream from $m N G(10.5 \pm 0.2$ a.u.). Hence, in G. oxydans and in case of $m N G$, termination of the target gene transcription close to the 3' end might be important to achieve higher expression levels in G. oxydans. None of the terminators appeared to affect the repression of $\mathrm{P}_{t e t}$ in the absence of ATc and a $\mathrm{P}_{t e t}$ leakiness was not observed.

\section{Comparison of the pBBR1MCS-2 / -5 backbones and insertion of AGGAGA as RBS}

The broad-host-range vectors pBBR1MCS-5 and pBBR1MCS-2 differ in the antibiotics resistance they convey for clone selection. pBBR1MCS-5 gmR encodes for a gentamicin-3-acetyltransferase enabling growth on gentamicin and pBBR1MCS-2 neoR/kanR encodes for a neomycin/kanamycin phosphotransferase enabling growth on kanamycin (Kovach et al. 1995). Furthermore, $g m R$ and $n e o R / k a n R$ are located on different DNA strands which in the case of neoR/kanR could result in transcripts partially overlapping with and antisense to the mRNA of the target gene present in the cloned insert. To check whether the plasmid backbone and antibiotics resistance affect the inducibility of $\mathrm{P}_{t e t}$ in G. oxydans we compared the performance of the TetR-P $\mathrm{P}_{\text {tet }}$ system with pBBR1MCS-5 and pBBR1MCS-2.

In G. oxydans the pBBR1MCS-2-based TetR-P $\mathrm{P}_{\text {tet }}$ system performed much worse compared to the pBBR1MCS5-based system despite the similarities of the two plasmids. With pBBR1MCS-2, the specific mNG fluorescence with induced $\mathrm{P}_{t e t}$ was almost halved and reached 19.2 \pm 9.7 a.u. $\sim 10 \mathrm{~h}$ after induction at the end of the exponential phase of growth, while with pBBR1MCS-5 the maximal fluorescence peaked at $36.7 \pm 2.2$ a.u. after $8 \mathrm{~h}$ (Fig. 3a). Nevertheless, the maximal induction ratios were high with both pBBR1MCS-2 and pBBR1MCS-5 and were calculated to be $1915 \pm 757$ and $3674 \pm 193$, respectively. The basal expression under non-induced conditions was not affected by the plasmid backbone. Notably, a much higher standard deviation was obtained with pBBR1MCS-2. FACS analysis with gating of cells in regard to their volume and complexity by forward and side scattering (FSC and SSC) of light revealed that a major part of the $G$. oxydans cells with the pBBR1MCS-2 derivative and kanamycin exhibited a very different non-typical elongated cell morphology that was not observed with the pBBR1MCS-5 derivative and gentamicin (Fig. 3b). Approximately only $42 \%$ of the population with the pBBR1MCS-2 derivative passed the FACS gate where almost $100 \%$ of $G$. oxydans cells without plasmid or with the pBBR1MCS-5 derivative passed. This high heterogeneity of G. oxydans carrying the pBBR1MCS-2 derivative was not affected by the inducer ATc. The occurrence of a portion of elongated cells with pBBR1MCS-2 backbone and kanamycin was also demonstrated by fluorescence microscopy (Fig. S4). Several G. oxydans cells carrying pBBR1MCS-2 or pBBR1MCS-2-tetR-P $\mathrm{P}_{t e t}-m N G-\mathrm{T}_{\mathrm{BBa} \_\mathrm{B} 1002} \mathrm{~T}_{0028}$ appeared to be $10-15 \mu \mathrm{m}$ and $>40 \mu \mathrm{m}$ long, while the $621 \mathrm{H}$ reference cells typically were $2-3 \mu \mathrm{m}$. Apparently, the altered 
a

pBBR1MCS-5-T $\mathrm{T}_{\text {gdh }}$-tetR-P $\mathrm{P}_{\text {tet }}-\mathrm{mNG}-\mathrm{T}_{\mathrm{BBa} \_ \text {B } 1002}-\mathrm{T}_{0028}$

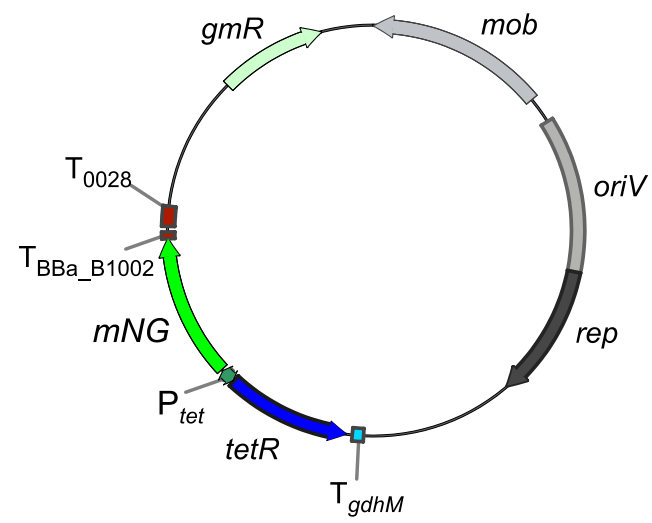

C

$T_{g d h M}$ $\frac{\text { gdhM }}{\text { GCCGGAACGAAAAAAGGGGAGATGCCTGATGGCATCTCCCCTTTTTCATGGCCCCG }}$

RBS

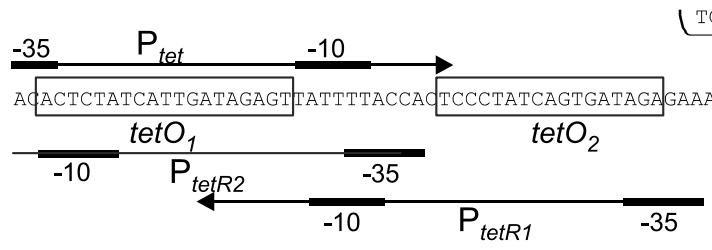

$\mathrm{T}_{0028}$

AGCTTGTCAGCATMAGACTGAAGTCTCGGTTCAGACAGATAAAAAAAGCCGGTCCCGCAAAGGGCCGGCTTTTTTGTGTCTCAGACCCGCCCTACGAACCGCTCGGGAACGCGC

d

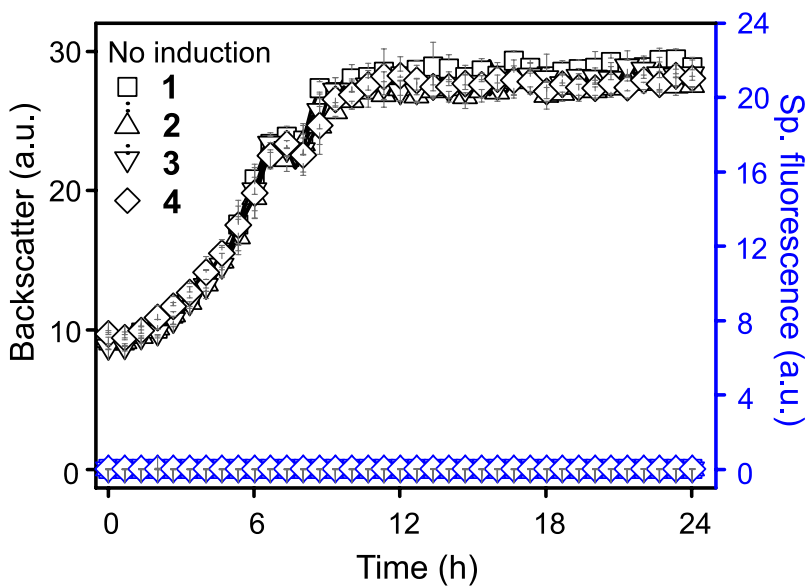

Fig. 2 Variants of pBBR1MCS-5-based expression plasmids with tetR- $P_{\text {tet }}$ and reporter gene expression in $G$. oxydans $621 \mathrm{H}$. a Map

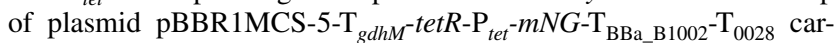
rying the fluorescence reporter gene mNeonGreen $(m N G)$ expressed from $\mathrm{P}_{t e t}$ with the adjacent tet $R$ gene and terminators $\mathrm{T}_{g d h M}$, $\mathrm{T}_{\mathrm{BBa} \_\mathrm{B} 1002}$ and $\mathrm{T}_{0028}$. b Variants of the plasmid insert with reporter gene $m N G$ to test TetR- $\mathrm{P}_{t e t}$-dependent expression in the presence and absence of terminators downstream from tetR and $m N G$, with RBS AGGAGA (Hentschel et al. 2013) inserted in the 3' region of $\mathrm{P}_{\text {tet }}$ upstream from $m N G$, and without tetR. c DNA sequence details with $\mathrm{P}_{t e t}$ region and TetR binding sites (tetO1 and tetO2) and termi-

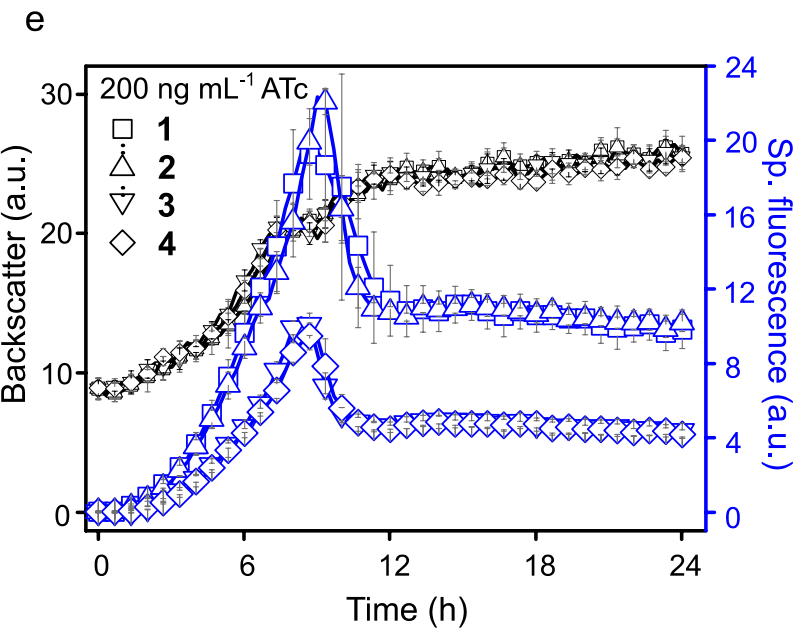

nator sequences adjacent to $t e t R$ and $m N G$. $\mathbf{d}+\mathbf{e}$ ) Growth according to backscatter and specific $\mathrm{mNG}$ fluorescence in $G$. oxydans carrying either plasmid pBBR1MCS-5- $\mathrm{T}_{g d h M^{-}}$tet $R-\mathrm{P}_{t e t}-m N G-\mathrm{T}_{\mathrm{BBa} \_\mathrm{B} 1002}-\mathrm{T}_{0028}$ (1), or the plasmid lacking $\mathrm{T}_{g d h M}$ (2) or $\mathrm{T}_{\mathrm{BBa} B 1002^{-} \mathrm{T}_{0028}}$ (3) or all terminators (4) under non-induced (d) and ATc-induced (e) condition in microscale BioLector cultivations. For induction $200 \mathrm{ng} \mathrm{mL}^{-1}$ ATc was present in the D-mannitol medium. Data represent mean values and standard deviation from two biological replicates with three technical replicates each. $\mathrm{T}_{g d h M}$ : terminator sequence of $g d h M$ (GOX0265); $\mathrm{T}_{0028}$ : terminator sequence of GOX0028. BioLector settings: backscatter gain 20 , fluorescence gain 50 
a

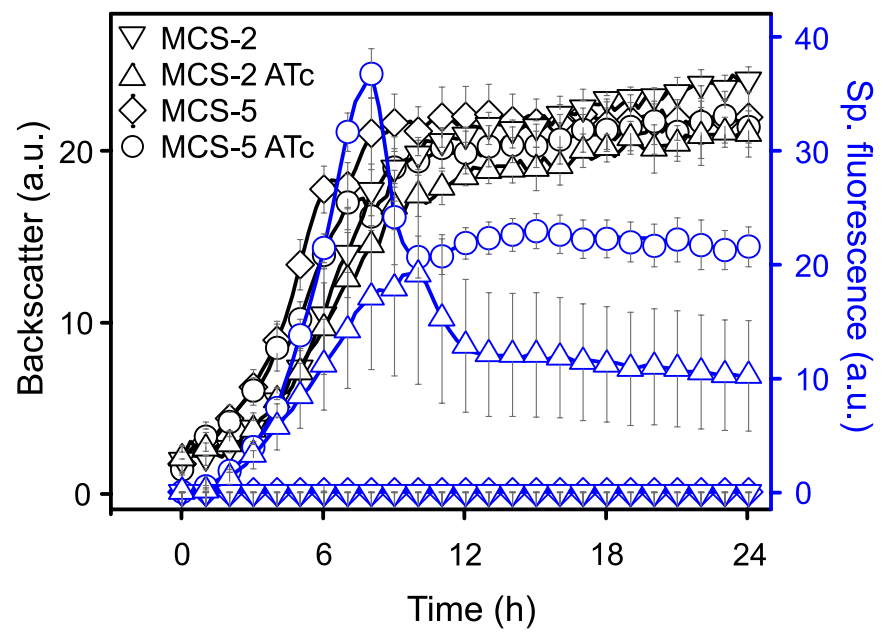

Fig. 3 Comparison of pBBR1MCS-5 and pBBR1MCS-2 with tetR$\mathrm{P}_{t e t}$ a Growth according to backscatter (gain 15) and specific mNeonGreen (mNG) fluorescence (gain 50) in G. oxydans $621 \mathrm{H}$ carrying either plasmid pBBR1MCS-5-T $\mathrm{T}_{g d h M}-t e t R-\mathrm{P}_{t e t}-m N G-\mathrm{T}_{\mathrm{BBa} \_\mathrm{B} 1002}-\mathrm{T}_{0028}$ or pBBR1MCS-2- $\mathrm{T}_{g d h M^{-}}$tet $R-\mathrm{P}_{t e t}-m N G-\mathrm{T}_{\mathrm{BBa} \_\mathrm{B} 1002}-\mathrm{T}_{0028}$ in microscale BioLector cultivations. For induction, always $200 \mathrm{ng} \mathrm{mL}^{-1}$ ATc was

a

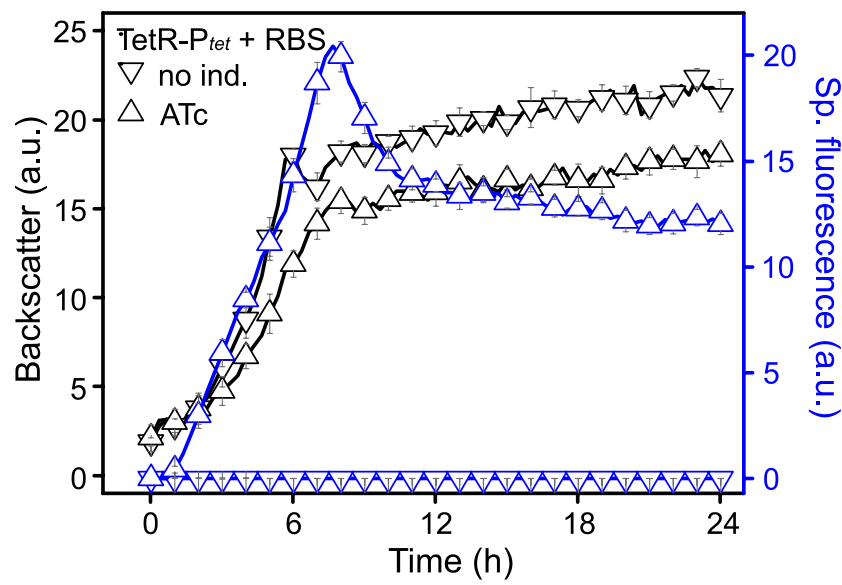

Fig. 4 Influence of the ribosome binding site AGGAGA on mNG reporter expression with the TetR-P $\mathrm{P}_{t e t}$ system. Growth according to backscatter and specific $\mathrm{mNeonGreen}(\mathrm{mNG})$ fluorescence in $G$. oxy-

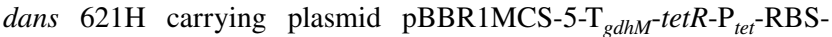
$m N G-\mathrm{T}_{\mathrm{BBa} B 1002}-\mathrm{T}_{0028}$ with the RBS change (a) and with plasmid

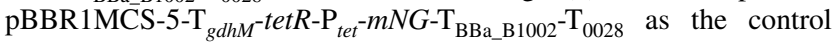

cell morphology had no direct effect on the inducibility of the TetR-P $\mathrm{P}_{\text {tet }}$ system in G. oxydans as elongated cells also exhibited strong $\mathrm{mNG}$ fluorescence.

To test improved translation and thus resulting reporter protein levels in G. oxydans, we also constructed a plasmid b

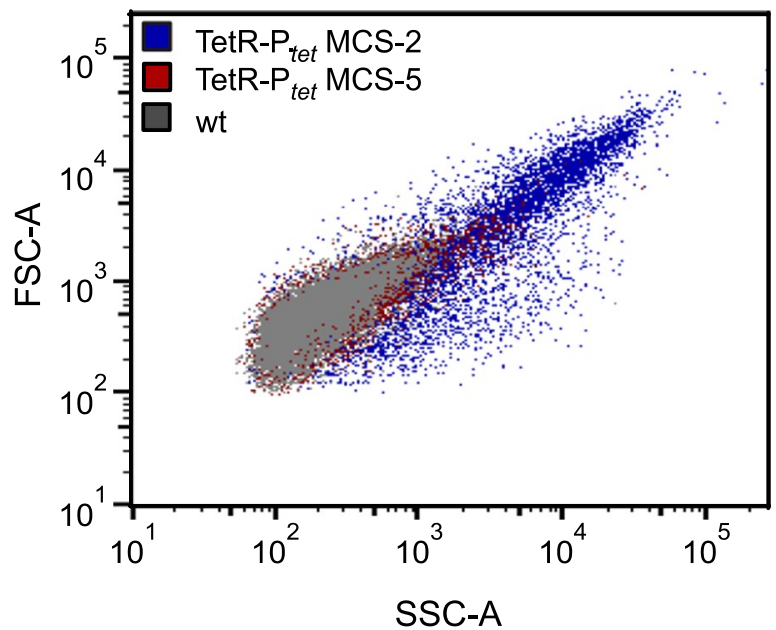

present in the D-mannitol medium. Data represent mean values and standard deviation from at least three biological replicates with three technical replicates each. b Cell morphology according to FACS analysis of $G$. oxydans $621 \mathrm{H}$ type strain (wt) without plasmid and with either the pBBR1MCS-5- or pBBR1MCS-2-based tetR-P ${ }_{\text {tet }}$ system, all without the inducer ATc

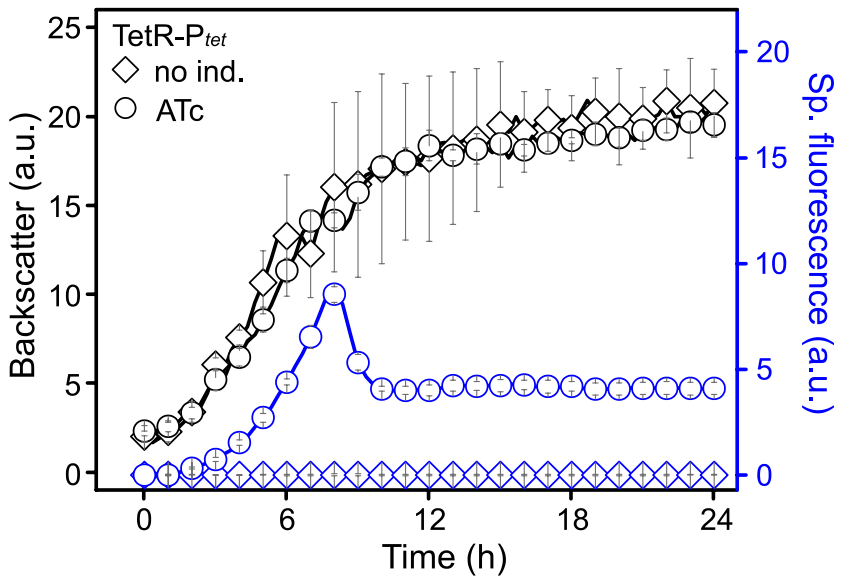

(b) in microscale BioLector cultivations. Cells were grown in D-mannitol medium without or with $200 \mathrm{ng} \mathrm{mL}^{-1}$ ATc for induction. Data represent mean values and standard deviation from two biological replicates with three technical replicates each. BioLector settings: backscatter gain 20, fluorescence gain 40

with the RBS AGGAGA that we had also used in the $\mathrm{araC}$ $\mathrm{P}_{\text {araBAD }}$ system and inserted it upstream from $m N G$ and downstream from tet $_{2}$ overlapping with the native RBS of the $\mathrm{P}_{\text {tet }}$ region (Fig. 2c). Thus, in this construct, $\mathrm{RBS}_{\text {Ptet }}$ and $\mathrm{RBS}_{\mathrm{AGGAGA}}$ were consecutively upstream from $m N G$. The 
impact on reporter expression and inducibility was measured in BioLector cultivations. Grown in D-mannitol medium and induced with $200 \mathrm{ng} \mathrm{mL}^{-1}$ ATc, the fluorescence signals of induced cells were further increased and reached $>4000$ fold induction, yet at such a high level that the detector gain in the BioLector had to be set from 50 down to 40 to avoid signal saturation. For both constructs with gain 40 setting, the insertion of RBS $_{\mathrm{AGGAGA}}$ doubled up the specific fluorescence in induced cells from $8.6 \pm 0.4$ a.u. for the reference to $20.4 \pm 0.5$ a.u. (Fig. 4). The basal expression in the absence of ATc was again extremely low, and the calculated maximal induction ratio based on the specific fluorescence with gain 40 was increased from $855 \pm 7$ for the reference to $2042 \pm 1$ for the plasmid with $\mathrm{RBS}_{\mathrm{AGGAGA}}$.

\section{pBBR1MCS-5-based Lacl-P lacUv5 $_{\text {was leaking }}$ and therefore tunable only up to 40 -fold}

For the lacI- $\mathrm{P}_{l a c}$ system, the insert containing lacI under control of its native promoter $\mathrm{P}_{\text {lact }}$, promoter $\mathrm{P}_{\text {lacUV5 }}$ and $l a c Z \alpha$ was derived from $E$. coli BL21(DE3). The promotor $\mathrm{P}_{\text {lacUV5 }}$ differs from the native $E$. coli $\mathrm{P}_{\text {lac }}$ promoter by three point mutations leading to enhanced activity and reduced cyclic adenosine monophosphate (cAMP)-dependency for induction in E. coli (Hirschel et al. 1980). Downstream from the $\mathrm{P}_{\text {lac } U V 5}$-controlled reporter gene $m N G$, the terminator $\mathrm{T}_{\mathrm{BBa} \_\mathrm{B} 1002}$ was placed and $\mathrm{RBS}_{\mathrm{AGGAGA}}$ upstream from $m N G$ (Fig. 5a, b). The lacI- $\mathrm{P}_{l a c}$ system includes three different operator sites which typically are bound by LacI in the absence of an inducer molecule to repress $\mathrm{P}_{\text {lac }}$-derived expression. Of these operator sites, $O_{1}$ is located in close proximity to the -10 region of $\mathrm{P}_{l a c}$, while $O_{3}$ and $O_{2}$ overlap with $l a c I$ and $l a c Z \alpha$, respectively. In $E$. coli all three operator sites are bound by tetrameric LacI and are required for maximal repression (Oehler et al. 1990). Therefore, in order to enable full repression by LacI, the $\alpha$-unit region of lacZ with $\mathrm{O}_{2}$ was included in the insert.

We examined the inducibility of $\mathrm{P}_{\text {lacUV5 }}$ by IPTG in G. oxydans $621 \mathrm{H}$ harboring the plasmid pBBR1MCS-5$\mathrm{P}_{\text {lacl }}$-lacI- $\mathrm{P}_{\text {lac UV5 }}-\mathrm{RBS}-m N G-\mathrm{T}_{\mathrm{BBa} \_\mathrm{B} 1002}-\mathrm{T}_{0028}$. Cells were grown in shake flasks using D-mannitol medium supplemented with and without $1 \mathrm{mM}$ IPTG. After $10 \mathrm{~h}$ at the end of the exponential growth phase, the highest fluorescence signal was measured. Due to the basal expression in the absence of IPTG, the maximal induction ratios by the absolute and by the specific fluorescence were calculated to be $18 \pm 4$ and $18 \pm 5$, respectively (Fig. $5 c$ ). When testing the inducibility of $\mathrm{P}_{\text {lac UV5 }}$ in microscale BioLector cultivations, a similar trend was observed. Under induced conditions, the fluorescence peaked approximately $6 \mathrm{~h}$ after induction and subsequently slightly decreased in the stationary phase while in non-induced cultures a basal fluorescence was measured (Fig. 5d). Here, with $1 \mathrm{mM}$ IPTG an average induction ratio of $41 \pm 16$ was calculated based on the specific fluorescence of the replicates in the BioLector. The $\mathrm{P}_{\text {lacUv5 }}$-derived $\mathrm{mNG}$ expression exhibited a tunability by IPTG concentrations ranging from 0.1 to $10 \mathrm{mM}$ in G. oxydans (Fig. 5e). The $m N G$ expression from $\mathrm{P}_{\text {lac UV5 }}$ was gradually increased up to $3 \mathrm{mM}$ IPTG. Above $3 \mathrm{mM}$ IPTG, the $m N G$ expression hardly increased further and thus appeared to be saturated and best-calculated induction ratios were again in the range of 40-fold. Illumina sequencing data obtained with total DNA purified from induced cells showed that $99.5 \%$ of the reads mapped to the updated reference sequences of the G. oxydans $621 \mathrm{H}$ genome, the 5 endogenous plasmids, and the mNG expression plasmid with lacI (Kranz et al. 2017). Thus, the sequencing results verified that the $\mathrm{P}_{l a c U V 5}$-derived $m N G$ expression was induced in $G$. oxydans carrying the intended plasmid pBBR1MCS-5-P lac I lacI-P $_{\text {lacUV5 }}$-RBS$m N G-\mathrm{T}_{\mathrm{BBa} \_\mathrm{B} 1002}-\mathrm{T}_{0028}$.

To analyze the induction of $\mathrm{P}_{\text {lacUV5 }}$ in G. oxydans on the single cell level with regard to the homogeneity of $m N G$ expression, flow cytometer analysis was applied (Fig. 5f). Within the chosen gate, $7 \mathrm{~h}$ after induction $95 \%$ of all induced cells exhibited high fluorescence $(\sim 11,000$ a.u.) while under non-induced conditions in $96 \%$ of all cells, the fluorescence was at the somewhat leaky basal level ( 1500 a.u.). This indicated that in the exponential growth phase, expression from induced $\mathrm{P}_{\text {lacUV5 }}$ was very homogenous in G. oxydans. This was also supported by fluorescence microscopy (Fig. S5).

Similarly, as for TetR and $\mathrm{P}_{t e t}$, we tested experimentally if initially lower medium $\mathrm{pH}$ values could affect the leakiness of $\mathrm{P}_{\text {lacUV5 }}$. Therefore, G. oxydans carrying the plasmid

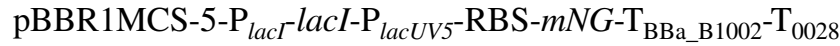
was grown in D-mannitol medium initially adjusted to $\mathrm{pH} 6$, 5,4 , and 3 in the absence and presence of IPTG. After $23 \mathrm{~h}$, cells were centrifuged and resuspended in fresh D-mannitolfree medium of $\mathrm{pH} 6$ to check for potential $\mathrm{pH}$-dependent recovery of $\mathrm{mNG}$ fluorescence above the respective levels monitored before that would indicate a higher leakiness of $\mathrm{P}_{\text {lacUV5 }}$ together with a previous loss of $\mathrm{mNG}$ fluorescence already during growth (Fig. S3e-h). In all non-induced cultures, overall basal fluorescence signals up to 10 a.u. were measured with decreasing maxima in the exponential phase when the initial medium $\mathrm{pH}$ decreased. Again, cells grown in $\mathrm{pH} 3$ exhibited the lowest signals and a different growth according to backscatter compared to all other cultures. Compared to the pH 6 condition, no sufficient increase of $\mathrm{mNG}$ fluorescence was observed in any non-induced $\mathrm{pH}$ condition $(6 \mathrm{~h})$ in the exponential growth phase to suggest a higher leakiness of $\mathrm{P}_{\text {lac UVV }}$. Additionally, after the transfer $(23 \mathrm{~h})$ of the non-induced cells into fresh D-mannitol-free medium adjusted to $\mathrm{pH} 6$ no recovery of $\mathrm{mNG}$ fluorescence above the levels with $\mathrm{pH} 6$ could be observed in any condition. Interestingly, only for the non-induced $\mathrm{pH} 4$ and $\mathrm{pH} 5$ 
a

b

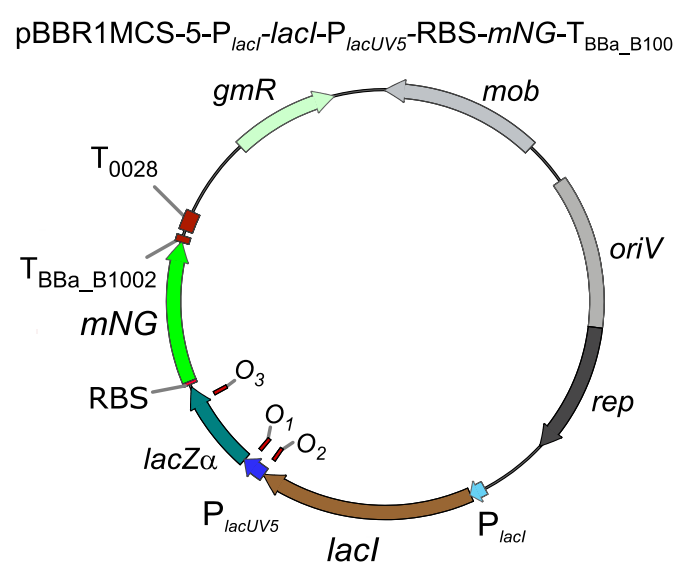

C
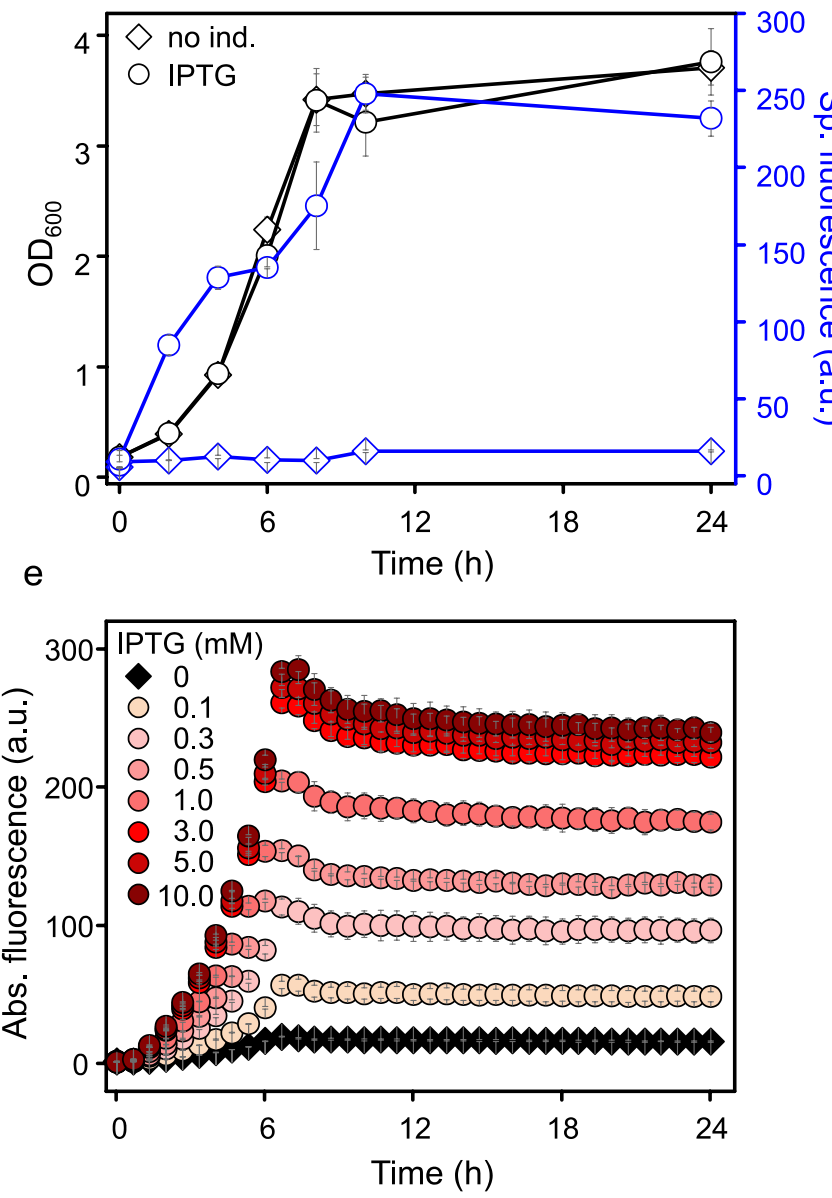

conditions, recovery of $\mathrm{mNG}$ fluorescence in $\mathrm{pH} 6(24 \mathrm{~h})$ above the respective maximal levels observed before in the exponential phase $(6 \mathrm{~h})$ were observed. This suggested that in the $\mathrm{pH} 4$ and $\mathrm{pH} 5$ conditions $G$. oxydans was not able to maintain its typical intracellular $\mathrm{pH}$ during growth and $\mathrm{mNG}$ d
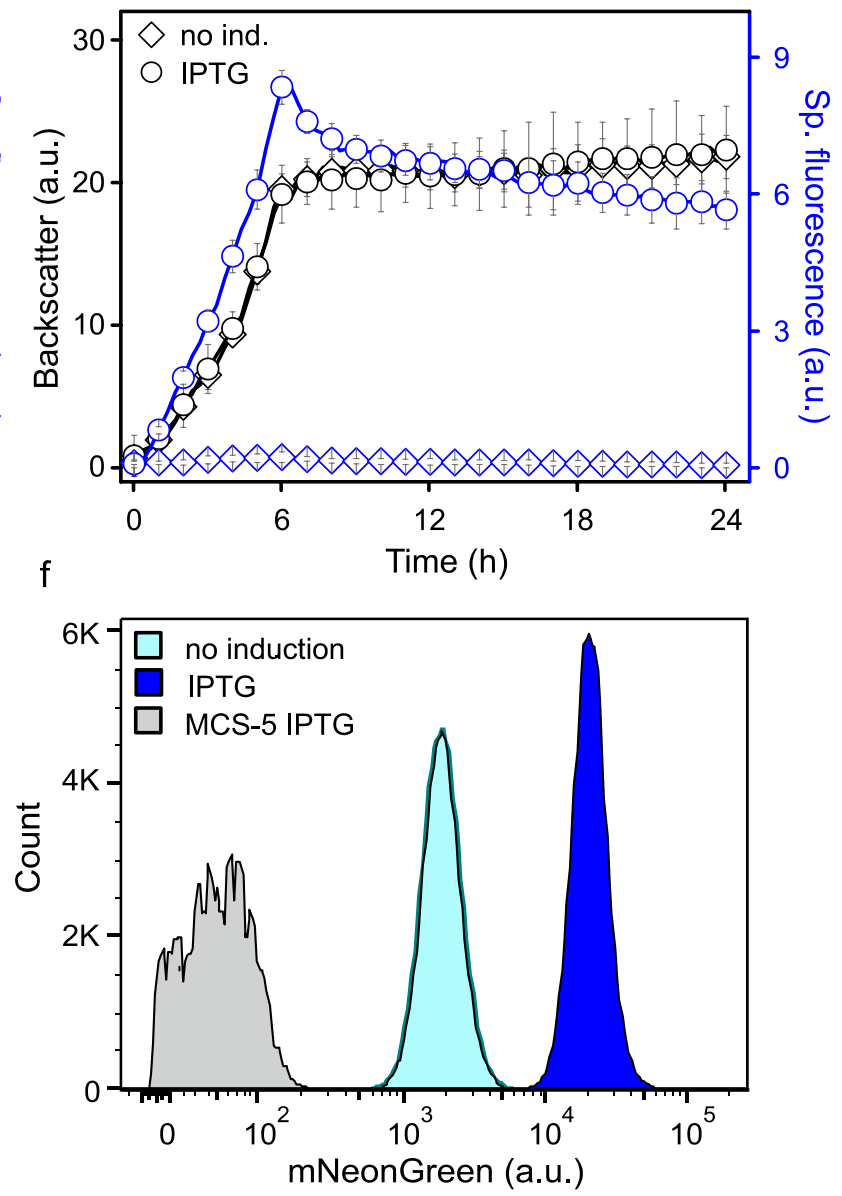

fluorescence partially became inactive already in an early phase of growth $(6 \mathrm{~h})$. 
4Fig. 5 pBBR1MCS-5-based expression plasmid with lacI-P lacUV5 and reporter gene expression in G. oxydans $621 \mathrm{H}$. a Map of the pBBR1MCS-5-based lacI- $\mathrm{P}_{\text {lacUV5 }}$ plasmid. b Sequence information details of the lacI- $\mathrm{P}_{\text {lacUv5 }}$ plasmid. The promoter $\mathrm{P}_{\text {lacUv5 }}$ comprises the LacI operator sites $\mathrm{O}_{3}, \mathrm{O}_{1}$, and $\mathrm{O}_{2}$. The $\mathrm{O}_{3}$ sites overlaps with the 3' end of lacI. The RBS AGGAGA was inserted upstream from $m N G$. The iGEM terminator sequence of BBa_B1002 was located downstream from $m N G$ followed by terminator $\mathrm{T}_{0028}$ from GOX0028. c Shake flasks cultivations of G. oxydans $621 \mathrm{H}$ carrying plasmid pBBR1MCS-5-P $\mathrm{P}_{\text {lac }}$-lacI-P $\mathrm{P}_{\text {lac } U V 5}-\mathrm{RBS}-m N G-\mathrm{T}_{\mathrm{BBa}-\mathrm{B} 1002}-\mathrm{T}_{0028}$ in IPTG-induced $(1 \mathrm{mM})$ and non-induced condition. The $\mathrm{mNG}$ fluorescence was measured in a Tecan reader (gain 60. The specific fluorescence was calculated from absolute fluorescence per $\mathrm{OD}_{600}$. d Microscale BioLector cultivations of $G$. oxydans $621 \mathrm{H}$ carrying plasmid pBBR1MCS-5-P $\mathrm{P}_{\text {lac }}$-lacI- $\mathrm{P}_{\text {lac UV5 }}-\mathrm{RBS}-m N G-\mathrm{T}_{\mathrm{BBa} \_\mathrm{B} 1002}-\mathrm{T}_{0028}$ in IPTG-induced $(1 \mathrm{mM})$ and non-induced condition. All data represent mean values and standard deviation from three biological replicates with three technical replicates each. Backscatter gain 15, fluorescence gain 60. e Microscale BioLector cultivations of $G$. oxydans $621 \mathrm{H}$ carrying plasmid pBBR1MCS-5- $\mathrm{P}_{\text {lac }}$-lacI- $\mathrm{P}_{\text {lac UV5 }}-\mathrm{RBS}-m N G-$ $\mathrm{T}_{\mathrm{BBa} B \mathrm{~B} 1002}-\mathrm{T}_{0028}$ with increasing concentrations of IPTG as indicated. Fluorescence gain 60. f FACS analysis of G. oxydans $621 \mathrm{H}$ carrying

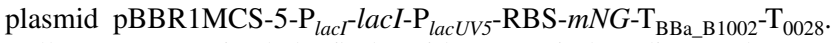
Cells were grown in shake flasks with D-mannitol medium and $1 \mathrm{mM}$ IPTG. FACS analysis was performed $7 \mathrm{~h}$ after inoculation and induction. Total counts per sample represent 100.000 events. As a control G. oxydans $621 \mathrm{H}$ carrying the empty vector pBBR1MCS-5 was used (MCS-5)

\section{Strength of $\mathbf{P}_{\text {lacUV5 }}$ was $\mathbf{P}_{\text {lacl }}$-lacl-dependent and leaking was independent of read-through}

Unlike most operons, in the E. coli lac operon, the regulatory gene lacI is located immediately upstream from the target operon and is transcribed in the same direction. The repressor LacI forms tetramers binding in the absence of an inducer to up to three operator sites, thereby preventing transcription from the lac promoter directly downstream from lacI. Nevertheless, despite LacI binding and the presence of a lacI terminator region coinciding with the LacI operator site $O_{1}$ directly downstream from the -10 region, readthrough is possible varying from 10 up to $80 \%$ (Horowitz and Platt 1982; Oehler et al. 1990). To check the possibility of read-through from $\mathrm{P}_{\text {lacI }}$ causing the leakiness observed in G. oxydans and interference by endogenous proteins on the $\mathrm{P}_{\text {lacUv5 }}$ inducibility, we wanted to check and compare the pBBR1MCS-5-based reporter expression in the absence of $\mathrm{P}_{\text {lacr }}$-lacI, as well as with $\mathrm{P}_{\text {lac }}$-lacI in opposite orientation toward $\mathrm{P}_{\text {lacUVV }}$.

Firstly, we constructed the plasmid pBBR1MCS-5$\mathrm{P}_{\text {lac UV5 }}$-RBS- $m N G-\mathrm{T}_{\mathrm{BBa} \_B 1002}-\mathrm{T}_{0028}$ lacking $\mathrm{P}_{\text {lacl }}$ and most of the lacI gene, while keeping a short 3' region of lacI to maintain all three operator sites of $\mathrm{P}_{\text {lacUV5 }}$ including $\mathrm{O}_{3}$ partly overlapping with the end of the lacI gene. The analysis of the IPTG-dependent inducibility of $\mathrm{P}_{\text {lac UV5 }}$ in G. oxydans in the absence of $\mathrm{P}_{\text {lac }}$-lacI revealed no difference in fluorescence signals supplemented with IPTG or not (Fig. S6). This indicated that the inducibility observed in G. oxydans solely depended on derepression by LacI. Interestingly, compared to the original system with $\mathrm{P}_{\text {lacl }}$-lacI, the maximal reporter expression from $\mathrm{P}_{\text {lacUV5 }}$ was strongly reduced from $8.4 \pm 0.4$ to $2.3 \pm 0.2$ according to the specific fluorescence $(6-7 \mathrm{~h})$ when $\mathrm{P}_{\text {lac }}$-lacI was lacking. This suggested that a significant read-through from $\mathrm{P}_{\text {lac }}$ appeared to contribute to the expression of the gene downstream from $\mathrm{P}_{\text {lacUV5 }}$, thus increasing the apparent $\mathrm{P}_{\text {lac UV5 }}$ strength in G. oxydans almost fourfold when induced.

Secondly, we constructed plasmid pBBR1MCS-5-lacI$\mathrm{P}_{\text {lac }}-\mathrm{P}_{\text {lac UV5 }}-\mathrm{RBS}-m N G-\mathrm{T}_{\mathrm{BBa} \_\mathrm{B} 1002}-\mathrm{T}_{0028}$ with $\mathrm{P}_{\text {lac }}$-lacI in opposite direction to exclude potential read-through toward $\mathrm{P}_{\text {lacUV5 }}$-mNG. Despite the opposite directions of $\mathrm{P}_{\text {lacl }}$ and $\mathrm{P}_{\text {lacUV5 }}$, an even somewhat higher leakiness of $\mathrm{P}_{\text {lacUV5 }}$ was observed when not induced (Fig. S7). Therefore, with $1 \mathrm{mM}$ IPTG the maximal induction fold-change $(6.4 \mathrm{~h})$ calculated was only $15.4 \pm 0.9$ based on the specific fluorescence, while the original $\mathrm{P}_{\text {lac }}$-lacI- $\mathrm{P}_{\text {lacUV5 }}$ construct reached a maximal induction fold-change $(6.7 \mathrm{~h})$ of $39.7 \pm 13.9$. Surprisingly, the apparent induced $\mathrm{P}_{\text {lac UV5 }}$ strength was restored according to the reporter fluorescence and reached the same levels as when $\mathrm{P}_{\text {lac }}$-lacI were in the same direction as $\mathrm{P}_{\text {lacUV5. }}$. Together, the results indicated that in G. oxydans the promoter strength of plasmid-based $\mathrm{P}_{\text {lac } U V 5}$ appeared to depend on sequences further upstream and that the $\mathrm{P}_{\text {lacUV5 }}$ leakiness was independent of potential read-through from $\mathrm{P}_{\text {lacl }}$.

\section{Modeling Lacl and TetR binding to DNA at acidic pH values}

Our results suggested that the leakiness of $\mathrm{P}_{\text {lac UV5 }}$ in G. oxydans was independent of potential read-through from $\mathrm{P}_{\text {lacl }}$ and thus should result from transcription initiation from $\mathrm{P}_{\text {lacUV5 }}$ and insufficient repression by LacI. Since the cytoplasmic $\mathrm{pH}$ of G. oxydans may readily be acidified to some extent already during growth when medium $\mathrm{pH}$ decreases, we modeled LacI- and TetR-DNA structures at different $\mathrm{pH}$ values using YASARA to predict if and how a potentially lower cytoplasmic hydrogen ion activity might affect the binding of LacI and TetR to DNA (Krieger et al. 2002). As a control, the AraC structure was also modeled since an L-arabinose-inducible AraC-P $\mathrm{P}_{a A B A D}$ system was shown to be fully functional in G. oxydans with plasmid pBBR1MSC-5, yet was very leaky in Gluconacetobacter and Komagataeibacter using another expression plasmid (Fricke et al. 2020; Teh et al. 2019). Protein-DNA bindings were simulated in two different steps for $\mathrm{pH} 7,6,5$, and 4 (see supplementary Text S1 and S2).

Analysis of the HADDOCK simulations in different $\mathrm{pH}$ conditions showed that the HADDOCK scores of all five best-scoring clusters obtained in the TetR-DNA dock-

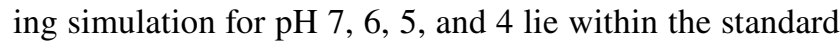




\section{DNA binding}

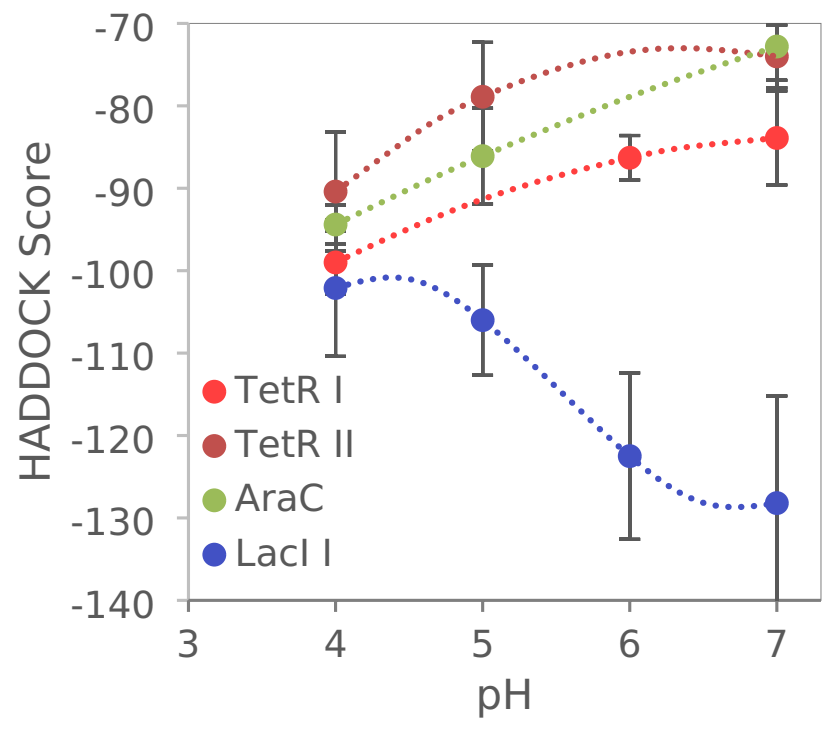

Fig. 6 Prediction of DNA-binding behavior of LacI, TetR, and AraC at different $\mathrm{pH}$ values computed by the HADDOCK web server. Each data point corresponds to a cluster of docking poses. The lower (more negative) the HADDOCK score the energetically more favorable the docking pose. Trend lines plotted are based on clusters containing similar docking poses. For details see supplementary Text S1 and Text S2

deviation of each other. To make a prediction of the DNA binding behavior in dependence of the $\mathrm{pH}$ value, similar docking positions were identified for each $\mathrm{pH}$ value and the cluster scores were compared. It can be observed that with decreasing $\mathrm{pH}$ values the scores decrease. The smaller the score, i.e., the more negative, the better is the predicted binding to DNA, suggesting an increased binding of TetR to DNA (Fig. 6). Similar results were obtained for AraC. Thus, when comparing the scores of clusters with corresponding docking positions, the values generally decreased with decreasing $\mathrm{pH}$ values, suggesting a generally increased binding to DNA for both TetR and AraC (Fig. 6). On the contrary, for LacI unique clusters with correlating docking

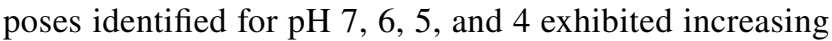
HADDOCK scores for decreasing $\mathrm{pH}$ values, suggesting a decreased DNA binding of LacI when pH decreases (Fig. 6 and Supplementary Text S1 and S2).

\section{Discussion}

In this study, we found with a pBBR1MCS-5-based TetR$\mathrm{P}_{\text {tet }}$ system that inducible target gene expression based solely on de-repression of the heterologous target promoter can also perform extremely well in G. oxydans. With the pBBR1MCS-5-based plasmid constructed here, the anhydrotetracycline (ATc)-inducible promoter $\mathrm{P}_{\text {tet }}$ derived from the $E$. coli transposon $\mathrm{Tn} 10$ exhibited excellently tunable expression performance in an inducer concentrationdependent manner with maximal induction ratios up to more than 3500-fold. This was due to extremely low basal reporter expression in the absence of an inducer, thus well repressed $\mathrm{P}_{t e t}$, and $\mathrm{P}_{\text {tet }}$ being very strong in G. oxydans.

In contrast, expression from $\mathrm{P}_{\text {lac } U V 5}$ was always leaky when not induced and this appeared to be independent of potential read-through from $\mathrm{P}_{\text {lacI }}$ which was located with lacI immediately upstream from $\mathrm{P}_{\text {lacUV5 }}$ and, unlike most regulator genes and target operons, coupled very close and transcribed in the same direction. Therefore, the transcription termination by the native lacI terminator is expected to be very effective in G. oxydans and the $\mathrm{P}_{\text {lacUV5 }}$ leakiness is rather related to the early events after transcription initiation from $\mathrm{P}_{\text {lac UV5 }}$. In E. coli, the LacI repressor is not preventing per se the binding of RNA polymerase (RNAP), but is blocking the progress of RNAP which has bound to the DNA and has begun transcribing (Reznikoff et al. 1969). Transcription through roadblocks has been shown to depend on the cooperation of the leading and trailing RNAP molecules and thus depends on how many RNAP molecules are allowed to initiate from the same promoter upstream from the roadblock (Epshtein et al. 2003; Hao et al. 2014). In the case of $\mathrm{P}_{l a c}$ or $\mathrm{P}_{\text {lac UVV }}$, the distance from the transcriptional start (TSS) to the LacI binding site $\mathrm{O}_{2}$ is rather short and site $O_{1}$ is even overlapping with the TSS; thus, only one RNAP molecule is expected to initiate upstream from the roadblock. Additionally, the E. coli $\sigma^{70}$ subunit of RNAP mediates a pause at the lac promoter closely downstream from the transcriptional start which is proposed to function in limiting the downstream gene expression (Nickels et al. 2004). If the $G$. oxydans $\sigma^{70}$ subunit of RNAP also mediates this pause at the lac promoter is unknown. Nevertheless, RNAP cooperation should not be possible and thus not contribute to the leakiness of $\mathrm{P}_{\text {lacUV5 }}$ in G. oxydans, yet the extent of read-through can also be affected by accessory factors. For example, in E. coli GreA and GreB rescue backtracked (roadblocked) RNAP by cleavage of the RNA, regenerating a new 3 ' end at the catalytic site, and can aid passage of RNAP through a LacI roadblock in cells (Toulme et al. 2000). Furthermore, in E. coli the transcription-coupled repair protein Mfd binds to the DNA behind RNAP and uses ATP to push backtracked RNAP forward until the 3' end of RNA is back at the catalytic center, yet the forces generated by Mfd may also result in RNAP termination (Park et al. 2002). E. coli GreA (158 aa, b3181) and G. oxydans GreA (157 aa, GOX0324) share 54\% sequence identity, E. coli GreB (158 aa, b3406) and G. oxydans GreB (168 aa, GOX1860) share 47\%, and E. coli Mfd (1148 aa, b1114) and G. oxydans Mfd (1173 aa, GOX0055) share 39\%. It is unknown how these factors support roadblocked RNAP and 
read-through behind roadblocks in G. oxydans and $\mathrm{AAB}$ in general, yet the leakiness of $\mathrm{P}_{l a c}$ or $\mathrm{P}_{\text {lac UV5 }}$ is likely rather related to weaker binding of LacI to operator DNA and thus weaker promoter repression in $G$. oxydans.

Our docking simulations predicted that below $\mathrm{pH} 6$ the binding of LacI to DNA is decreased which could cause or contribute to promoter leakiness. Neutralophilic bacteria maintain an intracellular $\mathrm{pH}$ between 7 and 8 , while in acidophilic bacteria intracellular $\mathrm{pH}$ is considered to be maintained between 6 and 7 (Baker-Austin and Dopson 2007; Krulwich et al. 2011). The mannitol LB medium typically used for $G$. oxydans is initially set to $\mathrm{pH} 6$ and can be acidified during growth in dependence of the carbon and energy sources, for example, to approximately $\mathrm{pH} 4.5$ or 3.3 as well (Fricke et al. 2020). In such acidic pH conditions of the growth medium strongly decreased, intracellular fluorescence reporter activities of $\mathrm{mNeonGreen}(\mathrm{mNG})$ were observed in G. oxydans in the stationary phase (Fricke et al. 2020). Studies with isolated $\mathrm{mNG}$ revealed a strong decrease in fluorescence at pH 4.4 and below (Steiert et al. 2018). Therefore, the decrease in $\mathrm{mNG}$ fluorescence in G. oxydans cells was attributed to an acidified intracellular $\mathrm{pH}$, at least in the stationary phase. The loss in $\mathrm{mNG}$ fluorescence in stationary G. oxydans cells can quickly be restored without protein synthesis just by short incubation in $\mathrm{pH} 6$ condition as shown in this study and before (Fricke et al. 2020). Moreover, for the AAB Acetobacter aceti, the intracellular $\mathrm{pH}$ was reported to change from 5.8 to 3.9 already during growth when the medium $\mathrm{pH}$ acidified from 6.2 to 3.5 (Menzel and Gottschalk 1985). Despite intracellular pH maintenance mechanisms, it is conceivable that depending on the growth conditions in some or many AAB the cytoplasmic $\mathrm{pH}$ can decrease already during growth below the range of pH 6 to 7 considered to be typically maintained in acidophilic bacteria. According to our data, the $\mathrm{mNG}$ reporter fluorescence in $G$. oxydans cells with LacI-P lacUV $_{5}$ grown in non-induced $\mathrm{pH} 4$ and $\mathrm{pH} 5$ conditions suggested that G. oxydans was not able to maintain its typical intracellular $\mathrm{pH}$ during growth and the $\mathrm{mNG}$ fluorescence became partially inactive already in the middle phase of growth $(6 \mathrm{~h})$. To get LacI-dependent systems tight and suitable for use in $G$. oxydans or AAB in general, the LacI protein may require engineering for increased binding to DNA in acidic $\mathrm{pH}$ condition. However, more intracellular $\mathrm{pH}$ data of $\mathrm{AAB}$ strains in various growth conditions are required. Besides leakiness, in G. oxydans, the strength of fully induced $\mathrm{P}_{\text {lac UV5 }}$ was much lower compared to that of the fully induced $\mathrm{P}_{t e t}$ (compare absolute fluorescence Fig. S3d and S3h). It was already reported before that $\mathrm{P}_{l a c}$ is rather weak in G. oxydans $621 \mathrm{H}$ and the $\mathrm{P}_{\text {lacUV5 }}$ mutant promoter exhibiting three base pair changes including two changes at positions -9 and -8 apparently also exhibits a similar low expression strength in G. oxydans (Hirschel et al. 1980; Kallnik et al. 2010). Thus, in $G$. oxydans the TetR-P $\mathrm{P}_{\text {tet }}$ system will probably always be the choice for applications because of its extremely low basal expression and very high dynamic range of the tunable expression strength from $\mathrm{P}_{t e t}$.

Interestingly, in $K$. rhaeticus iGEM, the TetR-P $\mathrm{P}_{t e t}$ system tested exhibited high leakiness in the absence of the inducer (Florea et al. 2016). In G. oxydans, we could neither observe nor demonstrate relevant leakiness of TetR$\mathrm{P}_{t e t}$, not with the $\mathrm{pBBR} 1 \mathrm{MCS}-5$-based construct variants ( \pm terminators), not with the pBBR1MCS-2 backbone and kanamycin causing abnormal cell morphology, and not in the media of the $\mathrm{pH}$ series. Without terminators downstream from $m N G$, the length of the $m N G$ transcript is assumed to exhibit an extended 3' UTR. This appeared to only decrease transcript stability or translation, since the $\mathrm{mNG}$ signals were reduced to half, yet repression of $\mathrm{P}_{\text {tet }}$ was not affected. For the tetR transcript, it is unknown how stability and translation are affected in G. oxydans when the 3' UTR is longer or shorter, yet altered repression of $\mathrm{P}_{\text {tet }}$ was also not observed with either of the constructs. A major difference of the two tetR- $\mathrm{P}_{\text {tet }}$ constructs tested in $K$. rhaeticus iGEM and in $G$. oxydans is that we maintained the opposite orientation of tetR- $\mathrm{P}_{t e t R}$ and $\mathrm{P}_{t e t}$ as originally present on $\mathrm{Tn} 10$, while in $K$. rhaeticus iGEM the construct tested contained the promoter $\mathrm{J} 23118$ or $\mathrm{P}_{\text {lacI }}$ for expression of tet $R$ followed by a terminator sequence and all directly upstream from the target promoter $\mathrm{P}_{\text {tet }}$ and in the same direction as $\mathrm{P}_{t e t}$ (Florea et al. 2016). It was assumed that the terminator is effective, yet it seemed to be unknown to what extend the terminator allowed potential read-through in these constructs. This could possibly cause the high leakiness of $\mathrm{P}_{\text {tet }}$ in K. rhaeticus iGEM, especially when cooperative RNAP molecules read through the TetR roadblock. On the other hand, our computational simulation also predicted that with decreasing $\mathrm{pH}$ value TetR dimerization decreases (Text S1 and Text S2). That could finally affect binding to DNA and thus promoter repression since TetR binds as a dimer (Hillen and Berens 1994). Thus, if the prediction holds true, in G. oxydans TetR dimerization is not sufficiently negatively affected by mild acidic intracellular pH. Komagataeibacter is typically grown in Hestrin - Schramm (HS) medium with glucose or in LGI medium with sucrose, both initially set to $\mathrm{pH} 6$ or $\mathrm{pH} 4.5$ and acidified further during growth (Florea et al. 2016; Hestrin and Schramm 1954). The intracellular $\mathrm{pH}$ of A. aceti was reported to change from 5.8 to 3.9 already during growth when the medium pH acidified from 6.2 to 3.5 (Menzel and Gottschalk 1985). The extent of being able to maintain the intracellular $\mathrm{pH}$ not only in the stationary phase but also during exponential growth could differ between AAB species. This could possibly be seen in the results with the LuxR-P $\mathrm{P}_{l u x}$ system in Komagataeibacter (Florea et al. 2016). The system exhibited condition-dependent induction only up to fivefold due to high leakiness, yet it also exhibited extremely low 
leakiness and much better induction performance according to fluorescence microscopic analysis in cells inside cellulose pellicles. Cellulose pellicles generate a micro-environment with the advantage of potentially protecting the cells from harsh conditions which could also include protection from acidic environmental $\mathrm{pH}$. Again, to better understand the $\mathrm{pH}$-dependent binding of regulators to DNA and to improve the expression performance of heterologous regulatable expressions systems so far leaky in $\mathrm{AAB}$ and their growth conditions, more intracellular $\mathrm{pH}$ data of $\mathrm{AAB}$ strains are required for various growth conditions. Additionally, experimental $\mathrm{pH}$-dependent protein-protein and protein-DNA interaction data are needed.

In summary, we could show that in G. oxydans the TetR$\mathrm{P}_{\text {tet }}$ system tested was extremely well performing with the pBBR1MCS-5 backbone and exhibited very strong reporter expression when induced, while the LacI-P $\mathrm{P}_{\text {lacUV5 }}$ system was always leaking and thus resulting in much lower induction ratios. Therefore, the pBBR1MCS-5-based TetR-P $\mathrm{P}_{t e t}$ system with the low inducer concentrations required for gradually tuning target gene expression appeared to be highly suitable for applications in G. oxydans and possibly in other AAB.

Supplementary Information The online version contains supplementary material available at https://doi.org/10.1007/s00253-021-11473-x.

Acknowledgements The authors are grateful to Uwe Deppenmeier for the kind gift of plasmid pBBR1-tetall-strep_long. The authors also thank Astrid Bida and Ulrike Viets for the technical assistance with the Illumina sequencing.

Author contribution PMF constructed the plasmids, carried out the growth experiments, and analyzed the data. PMF and CS performed the FACS analysis and analyzed the data. PMF and MH obtained the microscopic images. ML and MDD conducted the computational simulations. TP designed and supervised the study. PMF, ML, MDD, $\mathrm{MB}$, and TP wrote and revised the manuscript. All authors read and approved the final version.

Funding Open Access funding enabled and organized by Projekt DEAL. We are grateful to the Federal Ministry of Education and Research (BMBF) for the generous financial support of the project IMPRES (031B0370B). The funding organization did not influence the design of the study or collection, analysis, and interpretation of data, or writing the manuscript.

Data availability Data and material are available upon request.

\section{Declarations}

Ethical statement This article does not contain any studies with human participants or animals performed by any of the authors.

Conflict of interest The authors declare no competing interests.

Open Access This article is licensed under a Creative Commons Attribution 4.0 International License, which permits use, sharing, adaptation, distribution and reproduction in any medium or format, as long as you give appropriate credit to the original author(s) and the source, provide a link to the Creative Commons licence, and indicate if changes were made. The images or other third party material in this article are included in the article's Creative Commons licence, unless indicated otherwise in a credit line to the material. If material is not included in the article's Creative Commons licence and your intended use is not permitted by statutory regulation or exceeds the permitted use, you will need to obtain permission directly from the copyright holder. To view a copy of this licence, visit http://creativecommons.org/licenses/by/4.0/.

\section{References}

Altschul SF, Madden TL, Schaffer AA, Zhang JH, Zhang Z, Miller W, Lipman DJ (1997) Gapped BLAST and PSI-BLAST: a new generation of protein database search programs. Nucleic Acids Res 25(17):3389-3402. https://doi.org/10.1093/nar/25.17.3389

Ameyama M, Shinagawa E, Matsushita K, Adachi O (1981) D-fructose dehydrogenase of Gluconobacter industrius: purification, characterization, and application to enzymatic microdetermination of D-fructose. J Bacteriol 145(2):814-823

Baker-Austin C, Dopson M (2007) Life in acid: pH homeostasis in acidophiles. Trends Microbiol 15(4):165-171. https://doi.org/10. 1016/j.tim.2007.02.005

Bell CE, Lewis M (2000) A closer view of the conformation of the Lac repressor bound to operator. Nat Struct Biol 7(3):209-214

Condon C, Fitzgerald RJ, Ogara F (1991) Conjugation and heterologous gene expression in Gluconobacter oxydans ssp suboxydans. FEMS Microbiol Lett 80(2-3):173-178. https://doi.org/10.1016/ 0378-1097(91)90590-7

Eisenberg D, Luthy R, Bowie JU (1997) VERIFY3D: Assessment of protein models with three-dimensional profiles. Method Enzymol 277:396-404. https://doi.org/10.1016/S0076-6879(97)77022-8

Epshtein V, Toulme F, Rahmouni AR, Borukhov S, Nudler E (2003) Transcription through the roadblocks: the role of RNA polymerase cooperation. EMBO J 22(18):4719-4727. https://doi.org/10.1093/ emboj/cdg 452

Florea M, Hagemann H, Santosa G, Abbott J, Micklem CN, Spencer-Milnes X, Garcia LD, Paschou D, Lazenbatt C, Kong DZ, Chughtai H, Jensen K, Freemont PS, Kitney R, Reeve B, Ellis $\mathrm{T}$ (2016) Engineering control of bacterial cellulose production using a genetic toolkit and a new cellulose-producing strain. $\mathrm{P}$ Natl Acad Sci USA 113(24):E3431-E3440. https://doi.org/10. 1073/pnas. 1522985113

Fricke PM, Link T, Gätgens J, Sonntag C, Otto M, Bott M, Polen T (2020) A tunable L-arabinose-inducible expression plasmid for the acetic acid bacterium Gluconobacter oxydans. Appl Microbiol Biotechnol 104(21):9267-9282. https://doi.org/10.1007/ s00253-020-10905-4

Fricke PM, Klemm A, Bott M, Polen T (2021) On the way toward regulatable expression systems in acetic acid bacteria: target gene expression and use cases. Appl Microbiol Biotechnol 105(9):3423-3456. https://doi.org/10.1007/s00253-021-11269-z

Gibson DG, Young L, Chuang RY, Venter JC, Hutchison CA, Smith HO (2009) Enzymatic assembly of DNA molecules up to several hundred kilobases. Nat Methods 6(5):343-U41. https://doi. org/10.1038/Nmeth.1318

Gupta A, Singh VK, Qazi GN, Kumar A (2001) Gluconobacter oxydans: its biotechnological applications. J Mol Microb Biotech $3(3): 445-56$

Hanahan D (1983) Studies on transformation of Escherichia coli with plasmids. J Mol Biol 166(4):557-80

Hanwell MD, Curtis DE, Lonie DC, Vandermeersch T, Zurek E, Hutchison GR (2012) Avogadro: an advanced semantic chemical 
editor, visualization, and analysis platform. J Cheminformatics 4.https://doi.org/10.1186/1758-2946-4-17

Hao N, Krishna S, Ahlgren-Berg A, Cutts EE, Shearwin KE, Dodd IB (2014) Road rules for traffic on DNA - systematic analysis of transcriptional roadblocking in vivo. Nucleic Acids Res 42(14):8861-8872. https://doi.org/10.1093/nar/gku627

Hekmat D, Bauer R, Fricke J (2003) Optimization of the microbial synthesis of dihydroxyacetone from glycerol with Gluconobacter oxydans. Bioproc Biosyst Eng 26(2):109-16. https://doi.org/ 10.1007/s00449-003-0338-9

Hentschel E, Will C, Mustafi N, Burkovski A, Rehm N, Frunzke J (2013) Destabilized eYFP variants for dynamic gene expression studies in Corynebacterium glutamicum. Microb Biotechnol 6(2):196-201. https://doi.org/10.1111/j.1751-7915.2012.00360.x

Hestrin S, Schramm M (1954) Synthesis of cellulose by Acetobacter xylinum. II. Preparation of freeze-dried cells capable of polymerizing glucose to cellulose. Biochem J 58(2):345-52. https://doi. org/10.1042/bj0580345

Hillen W, Berens C (1994) Mechanisms underlying expression of Tn10-encoded tetracycline resistance. Annu Rev Microbiol 48:345-369. https://doi.org/10.1146/annurev.mi.48.100194. 002021

Hillen W, Gatz C, Altschmied L, Schollmeier K, Meier I (1983) Control of expression of the Tn10-encoded tetracycline resistance genes - equilibrium and kinetic investigation of the regulatory reactions. J Mol Biol 169(3):707-721. https://doi.org/10.1016/ S0022-2836(83)80166-1

Hirschel BJ, Shen V, Schlessinger D (1980) Lactose operon transcription from wild-type and L8-Uv5 lac promoters in Escherichia coli treated with chloramphenicol. J Bacteriol 143(3):1534-1537. https://doi.org/10.1128/Jb.143.3.1534-1537.1980

Horowitz H, Platt T (1982) A termination site for lacI transcription is between the CAP site and the lac promoter. J Biol Chem 257(19):11740-6

Jones DT (1999) Protein secondary structure prediction based on position-specific scoring matrices. J Mol Biol 292(2):195-202. https:// doi.org/10.1006/jmbi.1999.3091

Kallnik V, Meyer M, Deppenmeier U, Schweiger P (2010) Construction of expression vectors for protein production in Gluconobacter oxydans. J Biotechnol 150(4):460-465. https://doi.org/10.1016/j. jbiotec.2010.10.069

Khoury AM, Nick HS, Lu P (1991) In vivo interaction of Escherichia coli lac repressor $\mathrm{N}$-terminal fragments with the lac operator. J Mol Biol 219(4):623-34. https://doi.org/10.1016/0022-2836(91)90659-t

Kiefler I, Bringer S, Bott M (2017) Metabolic engineering of Gluconobacter oxydans $621 \mathrm{H}$ for increased biomass yield. Appl Microbiol Biotechnol 101(13):5453-5467. https://doi. org/10.1007/s00253-017-8308-3

Kortmann M, Kuhl V, Klaffl S, Bott M (2015) A chromosomally encoded T7 RNA polymerase-dependent gene expression system for Corynebacterium glutamicum: construction and comparative evaluation at the single-cell level. Microb Biotechnol 8(2):253-65. https://doi.org/10.1111/1751-7915.12236

Kovach ME, Elzer PH, Hill DS, Robertson GT, Farris MA, Roop RM 2nd, Peterson KM (1995) Four new derivatives of the broad-hostrange cloning vector pBBR1MCS, carrying different antibioticresistance cassettes. Gene 166(1):175-6. https://doi.org/10.1016/ 0378-1119(95)00584-1

Kranz A, Vogel A, Degner U, Kiefler I, Bott M, Usadel B, Polen T (2017) High precision genome sequencing of engineered Gluconobacter oxydans $621 \mathrm{H}$ by combining long nanopore and short accurate Illumina reads. J Biotechnol 258:197-205. https://doi.org/10.1016/j. jbiotec.2017.04.016

Krieger E, Koraimann G, Vriend G (2002) Increasing the precision of comparative models with YASARA NOVA - a self-parameterizing force field. Proteins 47(3):393-402. https://doi.org/10.1002/prot.10104
Krulwich TA, Sachs G, Padan E (2011) Molecular aspects of bacterial pH sensing and homeostasis. Nat Rev Microbiol 9(5):330-43. https:// doi.org/10.1038/nrmicro2549

Liu LP, Yang X, Zhao XJ, Zhang KY, Li WC, Xie YY, Jia SR, Zhong C (2020) A lambda Red and FLP/FRT-mediated site-specific recombination system in Komagataeibacter xylinus and its application to enhance the productivity of bacterial cellulose. ACS Synth Biol 9(11):3171-3180. https://doi.org/10.1021/acssynbio.0c00450

Mamlouk D, Gullo M (2013) Acetic Acid bacteria: physiology and carbon sources oxidation. Indian J Microbiol 53(4):377-84. https://doi. org/10.1007/s12088-013-0414-Z

Menzel U, Gottschalk G (1985) The internal $\mathrm{pH}$ of Acetobacterium wieringae and Acetobacter aceti during growth and production of acetic acid. Arch Microbiol 143(1):47-51. https://doi.org/10.1007/Bf00414767

Mientus M, Kostner D, Peters B, Liebl W, Ehrenreich A (2017) Characterization of membrane-bound dehydrogenases of Gluconobacter oxydans $621 \mathrm{H}$ using a new system for their functional expression. Appl Microbiol Biotechnol 101(8):3189-3200. https://doi.org/10. 1007/s00253-016-8069-4

Miller JH (1970). In: Beckwith JR, Zipser D (eds) The Lactose Operon. Cold Spring Harbor Laboratory Press, Cold Spring Harbor, pp 173-188

Nickels BE, Mukhopadhyay J, Garrity SJ, Ebright RH, Hochschild A (2004) The $\mathrm{s}^{70}$ subunit of RNA polymerase mediates a promoterproximal pause at the lac promoter. Nat Struct Mol Biol 11(6):544 550. https://doi.org/10.1038/nsmb757

Oehler S, Eismann ER, Kramer H, Muller-Hill B (1990) The three operators of the lac operon cooperate in repression. EMBO J 9(4):973-9

Olsson MHM, Sondergaard CR, Rostkowski M, Jensen JH (2011) PROPKA3: consistent treatment of internal and surface residues in empirical pK(a) predictions. J Chem Theory Comput 7(2):525-537. https://doi.org/10.1021/ct100578z

Pappenberger G, Hohmann HP (2014) Industrial production of L-ascorbic Acid (vitamin C) and D-isoascorbic acid. Adv Biochem Eng Biotechnol 143:143-88. https://doi.org/10.1007/10_2013_243

Park JS, Marr MT, Roberts JW (2002) E. coli transcription repair coupling factor (Mfd protein) rescues arrested complexes by promoting forward translocation. Cell 109(6):757-767. https://doi.org/10.1016/ S0092-8674(02)00769-9

Qiu J, Elber R (2006) SSALN: an alignment algorithm using structuredependent substitution matrices and gap penalties learned from structurally aligned protein pairs. Proteins 62(4):881-891. https:// doi.org/10.1002/prot.20854

Reznikoff WS, Miller JH, Scaife JG, Beckwith JR (1969) A mechanism for repressor action. J Mol Biol 43(1):201. https://doi.org/10.1016/ 0022-2836(69)90089-8

Saito Y, Ishii Y, Hayashi H, Imao Y, Akashi T, Yoshikawa K, Noguchi Y, Soeda S, Yoshida M, Niwa M, Hosoda J, Shimomura K (1997) Cloning of genes coding for L-sorbose and L-sorbosone dehydrogenases from Gluconobacter oxydans and microbial production of 2-keto-L-gulonate, a precursor of $\mathrm{L}$-ascorbic acid, in a recombinant G oxydans strain. Appl Environ Microb 63(2):454-60

Sambrook J, Fritsch EF, Maniatis T (1989) Molecular cloning: a laboratory manual. Cold Spring Harbor Laboratory Press, Cold Spring Harbor

Schleif R (2010) AraC protein, regulation of the L-arabinose operon in Escherichia coli, and the light switch mechanism of AraC action. FEMS Microbiol Rev 34(5):779-96. https://doi.org/10.1111/j.15746976.2010.00226.x

Sellitti MA, Pavco PA, Steege DA (1987) lac repressor blocks in vivo transcription of lac control region DNA. P Natl Acad Sci USA 84(10):3199-203. https://doi.org/10.1073/pnas.84.10.3199

Shaner NC, Lambert GG, Chammas A, Ni Y, Cranfill PJ, Baird MA, Sell BR, Allen JR, Day RN, Israelsson M, Davidson MW, Wang J (2013) A bright monomeric green fluorescent protein derived from 
Branchiostoma lanceolatum. Nat Methods 10(5):407-9. https://doi. org/10.1038/nmeth.2413

Simon R, Priefer U, Pühler A (1983) A broad host range mobilization system for in vivo genetic-engineering - transposon mutagenesis in Gram-negative bacteria. Bio-Technol 1(9):784-791. https://doi.org/ $10.1038 /$ nbt1183-784

Sippl MJ (1993) Recognition of errors in 3-dimensional structures of proteins. Proteins 17(4):355-362. https://doi.org/10.1002/prot.340170404

Steiert F, Petrov EP, Schultz P, Schwille P, Weidemann T (2018) Photophysical behavior of $\mathrm{mNeonGreen,} \mathrm{an} \mathrm{evolutionarily} \mathrm{distant} \mathrm{green}$ fluorescent protein. Biophys J 114(10):2419-2431. https://doi.org/ 10.1016/j.bpj.2018.04.013

Stenberg KAE, Vihinen M (2009) Crystal structure of a 1,6-hexanediol bound tetrameric form of Escherichia coli lac-repressor refined to 2.1 A resolution. Proteins 75(3):748-759. https://doi.org/10.1002/ prot. 22284

Teh MY, Ooi KH, Teo SXD, Bin Mansoor ME, Lim WZS, Tan MH (2019) An expanded synthetic biology toolkit for gene expression control in Acetobacteraceae. ACS Synth Biol 8(4):708-723. https:// doi.org/10.1021/j.acssynbio.8b00168

Tkac J, Navratil M, Sturdik E, Gemeiner P (2001) Monitoring of dihydroxyacetone production during oxidation of glycerol by immobilized Gluconobacter oxydans cells with an enzyme biosensor. Enzyme Microb Tech 28(4-5):383-388
Toulme F, Mosrin-Hauman C, Sparkowski J, Das A, Leng M, Rahmouni AR (2000) GreA and GreB proteins revive backtracked RNA polymerase in vivo by promoting transcript trimming. EMBO J 19(24):6853-6859. https://doi.org/10.1093/emboj/19.24.6853

van Zundert GCP, Rodrigues J, Trellet M, Schmitz C, Kastritis PL, Karaca E, Melquiond ASJ, van Dijk M, de Vries SJ, Bonvin A (2016) The HADDOCK2.2 web server: User-friendly integrative modeling of biomolecular complexes. J Mol Biol 428(4):720-725. https://doi.org/10.1016/j.jmb.2015.09.014

Wang EX, Ding MZ, Ma Q, Dong XT, Yuan YJ (2016) Reorganization of a synthetic microbial consortium for one-step vitamin $\mathrm{C}$ fermentation. Microb Cell Fact 15:21. https://doi.org/10.1186/ s12934-016-0418-6

Wray LV Jr, Reznikoff WS (1983) Identification of repressor binding sites controlling expression of tetracycline resistance encoded by Tn10. J Bacteriol 156(3):1188-91. https://doi.org/10.1128/JB.156.3. 1188-1191.1983

Publisher's note Springer Nature remains neutral with regard to jurisdictional claims in published maps and institutional affiliations. 